\title{
Control of polarized assembly of actin filaments in cell motility
}

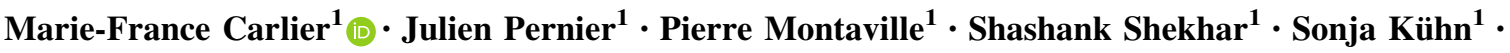 \\ Cytoskeleton Dynamics and Motility group
}

Received: 27 January 2015/Revised: 2 April 2015/Accepted: 23 April 2015/Published online: 7 May 2015

(C) The Author(s) 2015. This article is published with open access at Springerlink.com

\begin{abstract}
Actin cytoskeleton remodeling, which drives changes in cell shape and motility, is orchestrated by a coordinated control of polarized assembly of actin filaments. Signal responsive, membrane-bound protein machineries initiate and regulate polarized growth of actin filaments by mediating transient links with their barbed ends, which elongate from polymerizable actin monomers. The barbed end of an actin filament thus stands out as a hotspot of regulation of filament assembly. It is the target of both soluble and membrane-bound agonists as well as antagonists of filament assembly. Here, we review the molecular mechanisms by which various regulators of actin dynamics bind, synergize or compete at filament barbed ends. Two proteins can compete for the barbed end via a mutually exclusive binding scheme. Alternatively, two regulators acting individually at barbed ends may be bound together transiently to terminal actin subunits at barbed ends, leading to the displacement of one by the other. The kinetics of these reactions is a key in understanding how filament length and membrane-filament linkage are controlled. It is also essential for understanding how force is produced to shape membranes by mechano-sensitive, processive barbed end tracking machineries like formins and by WASP-Arp $2 / 3$ branched filament arrays. A combination of biochemical and biophysical approaches, including bulk solution assembly measurements using pyrenyl-actin fluorescence, single filament dynamics, single molecule fluorescence imaging and reconstituted self-organized
\end{abstract}

Marie-France Carlier

carlier@1ebs.cnrs-gif.fr

1 Institut de Biologie Intégrative de la Cellule, CNRS, 91198 Gif-sur Yvette, France filament assemblies, have provided mechanistic insight into the role of actin polymerization in motile processes.

Keywords Actin filament barbed end · Treadmilling · Processivity · Formins - WH2 domains · WASP family proteins · Arp2/3 complex . Filament branching · Capping proteins · Profilin · Cell protrusion

\section{Introduction}

The actin cytoskeleton is a dynamic architecture of the living cell, made of several structurally and functionally distinct arrays of actin filaments that define modular motile activities. Nucleation and polarized assembly of actin filaments are driven locally in a stimulus-responsive fashion in each module by specific protein machineries. These reactions develop forces of compression or traction against the membranes to elicit protrusive, adhesive and contractile activities ([1] for review). Dendritic arrays of branched filaments are assembled at the leading edge of lamellipodia, at the neck of endocytic vesicles, in podosomes. Linear actin bundles are arranged in parallel fashion in filopodia and microspikes within lamellipodia, and in antiparallel fashion in contractile stress fibers. Cells thus use actin to move, feed, divide, and organize intracellular traffic. These actin-based machineries are also harnessed by intracellular pathogens to propel themselves and facilitate their propagation ([2] for review).

A large number of experiments have established that the dynamic nature of the actin cytoskeleton is essential for motility. Movement is abolished if cells are treated with drugs that either depolymerize or stabilize actin filaments. Actin filament polarized assembly in a motile cell has been 
demonstrated by a number of live-cell imaging methods such as fluorescence recovery after photobleaching (FRAP), fluorescence loss in photobleaching (FLIP), fluorescence localization after photobleaching (FLAP), and fluorescence speckle microscopy (FSM) [3, 4]. To gain a fundamental understanding of cell motility, it is essential to understand how actin assembly is spatially and kinetically maintained and controlled in cells.

In a living cell, actin is in a dynamic equilibrium (or rather steady-state) between two states-the globular monomeric state (G-actin) and the polymeric filament state (F-actin). At physiological ionic strength, actin is essentially polymerized in filaments (F-actin). Movement is intimately linked to actin exchanges between these two states. These exchanges are dissipative due to ATP hydrolysis that is associated with actin assembly ([5] for review). This is why in a living cell actin is assembled at a steady-state, in contrast to equilibrium polymers assembled by reversible association-dissociation reactions. Because the assembly-disassembly kinetics are faster at the barbed ends than at the pointed ends as compared to the rate of ATP hydrolysis, terminal actin subunits at barbed ends are mostly ATP or ADP-Pi bound, while ADP-actin is mainly exposed to the pointed end (Fig. 1a, b). The resulting energetic bias in monomer-polymer exchanges at the two ends generates a net flux of subunits from one end to the other, called treadmilling, which is intrinsically extremely slow for pure actin (See Fig. 1 for detailed information). It is therefore only via the regulation of treadmilling by actinbinding proteins that fast polarized actin assembly can occur in cells.

The relative sizes of the assembled and unassembled actin pools are regulated in several ways, which are interconnected. The mechanically simplest regulators are G-actin sequestering proteins. Proteins such as $\beta$-thymosins bind G-actin in a complex that does not assemble in filaments. This pool of sequestered actin is in rapid equilibrium with only G-actin, not with F-actin, and cannot be invoked to support actin assembly directly. It can only amplify the changes in amount of F-actin that result from changes in stationary concentration of free monomers, elicited by regulators of assembly dynamics at filament barbed ends. In contrast with G-actin sequestering proteins, profilin binds G-actin in a complex that participates in barbed end assembly specifically (Fig. 1b), thus enhancing the processivity of treadmilling.

Live-cell imaging of actin filament dynamics in lamellipodia of migrating cells indicates that filaments treadmill at constant rate as the leading edge moves forward [3, 4]. Similarly, pathogens like Listeria monocytogenes, which exploit actin-based motility, move in the cytoplasm at constant rates for long periods of time [6,7]. These features indicate that movement is mediated by the steady-state turnover of actin filaments. They are incompatible with other evoked mechanisms such as a sudden increase in availability of large amounts of G-actin [1], which would generate sudden transient movements that would exponentially slow down to arrest upon reaching steady-state, as observed in a test tube when G-actin is induced to assemble at time zero.

In the cellular context, fundamental questions regarding the mechanism of production of force and movement by actin polymerization remain unanswered. For polarized growth of filaments to be maintained at defined sites in the cell, e.g., at the protein-membrane interface, some transient attachment of the growing barbed ends appears to be required. What structural and functional mechanisms are able to locally restrain and control filament growth? How are these chemical reactions at the interface of filaments and membranes transduced into mechanical properties, at the molecular and supramolecular scale? What laws of physical chemistry of protein self-assembly account for coordinated filament turnover in various arrays and for actin homeostasis? If dendritic arrays are assembled using the same basic molecules in different motile functions, how does the cell avoid indirect effects resulting from one motile activity (e.g. endocytosis) on the efficiency of other modules? Answering these questions requires a detailed understanding of the underlying molecular mechanisms at high spatial and temporal resolution. Integrated interdisciplinary approaches have shown promise of providing answers at different scales to these burning issues.

\section{The barbed end of the actin filament: a hotspot of actin assembly regulation}

An actin filament is a chiral helical polymer in which all actin subunits share the same polarity, defining a "barbed end" and a "pointed end" (Figs. 1b, 2). A large number of proteins control actin dynamics by binding the barbed face of actin. The barbed face of actin is exposed on G-actin and also on the two terminal subunits (the ultimate and penultimate protomers, at positions B1 and B2 in Fig. 2c) of the filament barbed end. This feature introduces several levels of potential complexity in the regulation.

First, the two terminal subunits are subject to weaker bonding constraints compared to the actin subunits further in the core of the filament, which are connected via two lateral and two longitudinal contacts. The acknowledged structural plasticity of the filament core [8] is potentially enhanced at the barbed ends, which might be exploited by regulators to generate a large variety of functional states. The actual structure of these two subunits is not known, but they might adopt a conformation closer to that of G-actin (Fig. 2a) than to the F-actin subunits in the core of the 


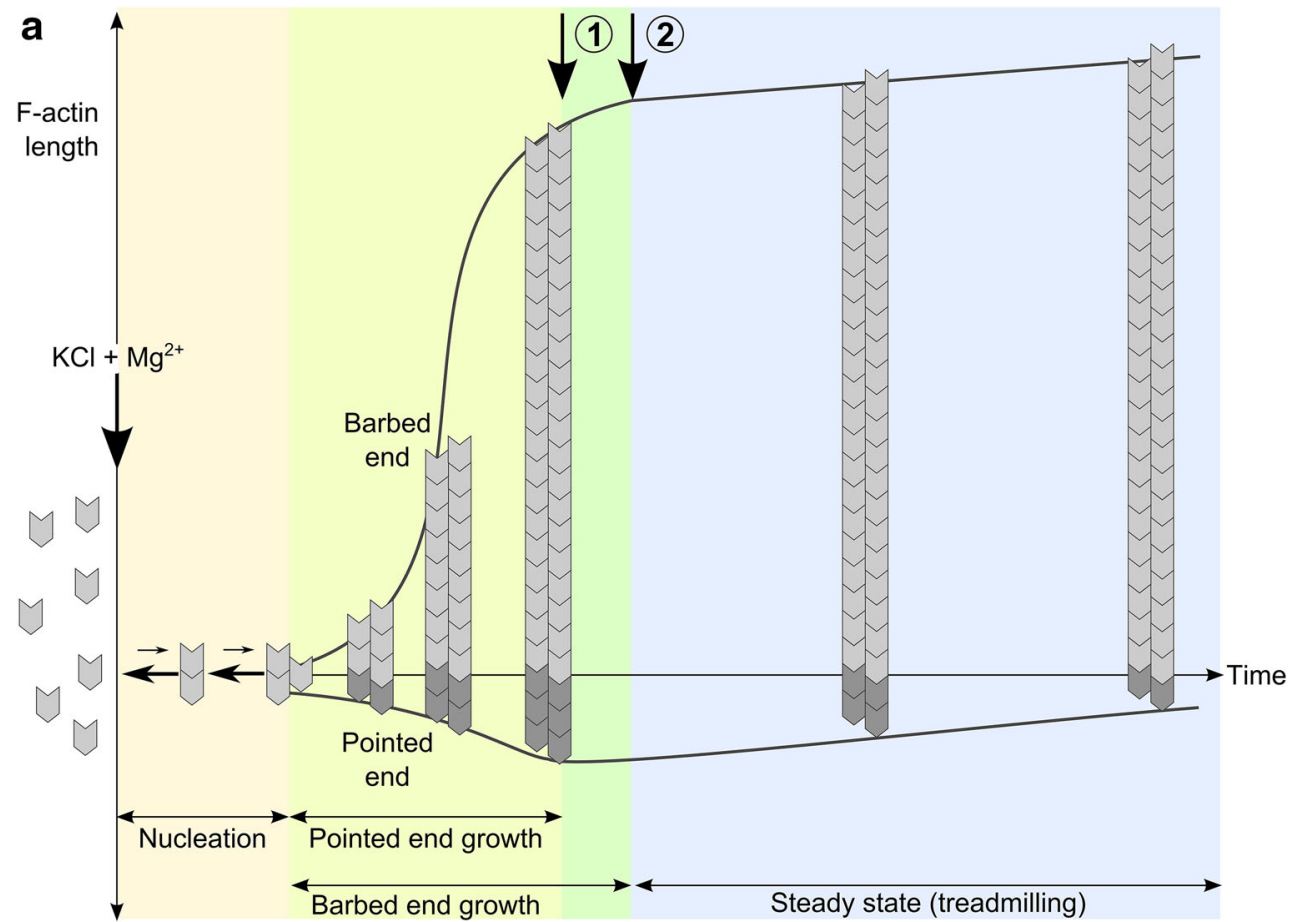

b

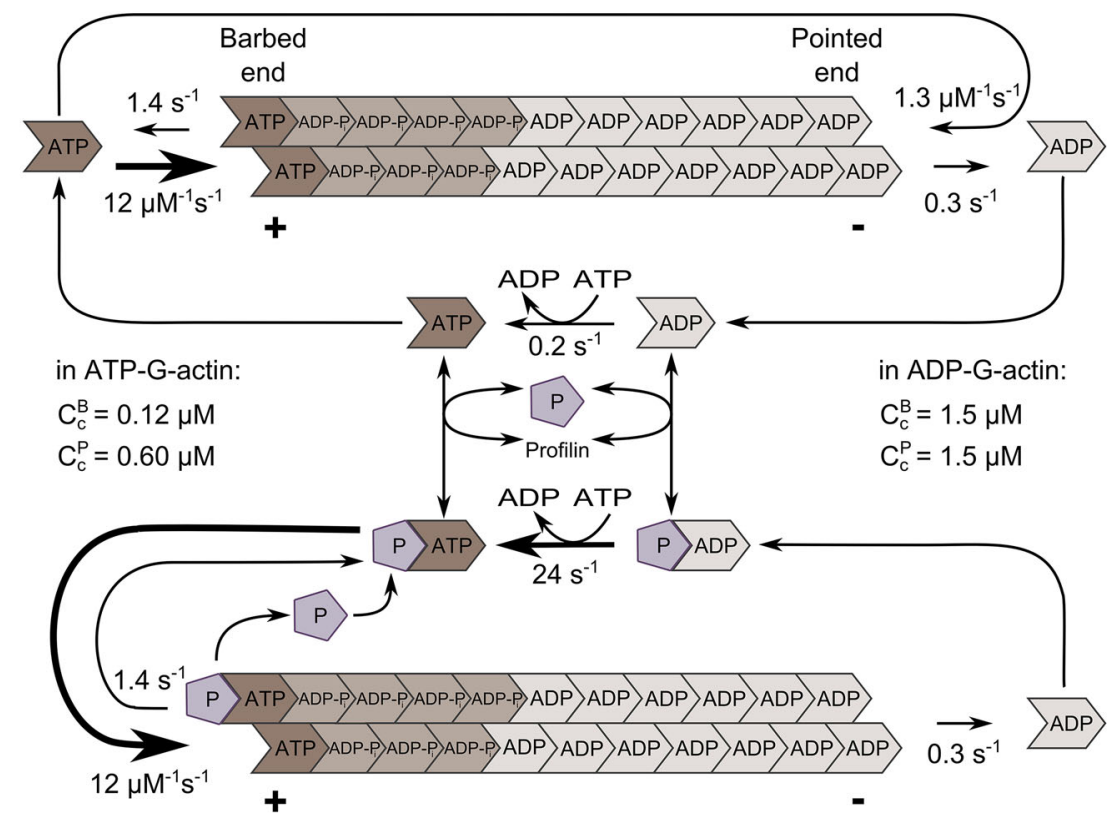

Fig. 1 Diagram of self-assembly of an "average" actin filament in vitro. a Spontaneous assembly of ATP-actin in vitro is initiated by a sudden increase in ionic strength at time zero, in a solution of actin monomers (G-actin). Nucleation is followed by endwise association of G-actin molecules to nuclei, faster at the barbed end than at the pointed end. As F-actin is assembled, the concentration of G-actin monomers decreases in solution. Pointed end growth rate reaches zero (arrow 1) when the concentration of G-actin reaches the critical concentration for pointed end assembly $(0.6 \mu \mathrm{M})$. Barbed end growth goes on and G-actin concentration declines, while pointed ends start to disassemble. When the steady-state concentration of G-actin $(0.1 \mu \mathrm{M})$ is reached (arrow 2), equal net rates of barbed end assembly and pointed end disassembly (treadmilling) maintain a constant amount of F-actin in solution, schematized here by a constant length of the "average" filament. b Nucleotide hydrolysis associated with the treadmilling cycle of the actin filament at steady-state in ATP, with and without profilin. The barbed end terminal subunits are enriched in ATP/ADP-Pi, while ADP is bound to pointed end terminal subunits. Profilin-ATP-actin participates in barbed end assembly, but not in pointed end assembly, hence it enhances processivity of treadmilling. In the cellular medium, treadmilling is regulated to generate variable rates of barbed end assembly. Regulation is performed either by increasing the rate limiting step of the treadmilling cycle which is pointed end depolymerization (using ADF/cofilin), or by regulating the dynamics at barbed ends (capping, tracking, destabilizing) 
$(-)$

pointed face

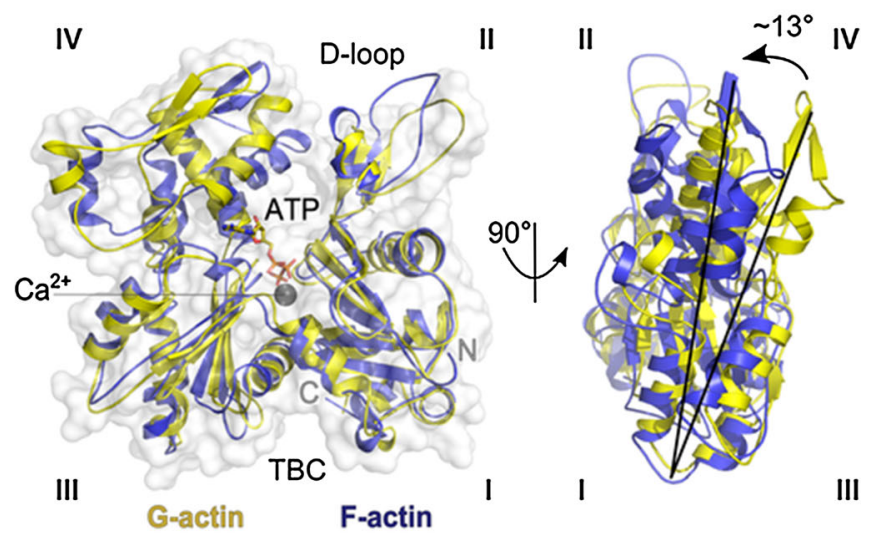

(+)

barbed face

Fig. 2 Structures of G-actin and F-actin filament barbed ends. a The transition of G- to F-actin. The structures of actin in the globular G-actin (yellow) or in the filamentous F-actin (blue) state are superimposed. They originate from G-actin in complex with DNAse I with bound $\mathrm{Ca}^{2+}$-ion and ATP (1ATN; [122]) and F-actin (2ZWH; [123]). The DNAse I-binding loop (D-loop) and subdomains $I-I V$ are labeled. The target binding cleft (TBC) at the barbed face of actin is located between subdomains $I$ and $I I I$. Actin protomers are flattened in F-actin by a $13^{\circ}$ twist of the outer subdomains ( $I$ and $\left.I I\right)$ to the inner ones (III and $I V$ ). b Surface representation of the double-helical

filament in which the subdomains twist into a "flatter" structure (Fig. 2b). "Primary" regulators that interact with the terminal actin subunits at the barbed end may either facilitate or prevent further binding of "secondary" regulators, thereby building up structurally distinct filament arrays. The nucleotide state of the terminal subunits i.e., ATP, ADP-Pi or ADP may modulate the affinity of various regulators for the barbed end of the filament, potentially increasing the complexity of the regulation.

Second, barbed end binding proteins may associate either with only one or both actins at the barbed ends (Fig. 3). Occupancy of the barbed face by a regulator leaves the barbed face of the penultimate subunit available for interaction with other regulators. On terminal actin subunits, binding regions are shared by several regulators and additional binding regions are specific to individual regulators. Thus, complexes in which two regulators are bound together at filament barbed ends are potentially formed, pending lowered affinity (Fig. 3). This may lead to far more complex mechanistic schemes for barbed end regulation than the simple models merely relying on mutually exclusive binding.

A frequently used binding site, targetted by actin-binding proteins as well as by drugs like macrolides, is the hydrophobic pocket in the shear zone between subdomains 1 and 3 also called target binding cleft, TBC (Figs. 2a, 3).
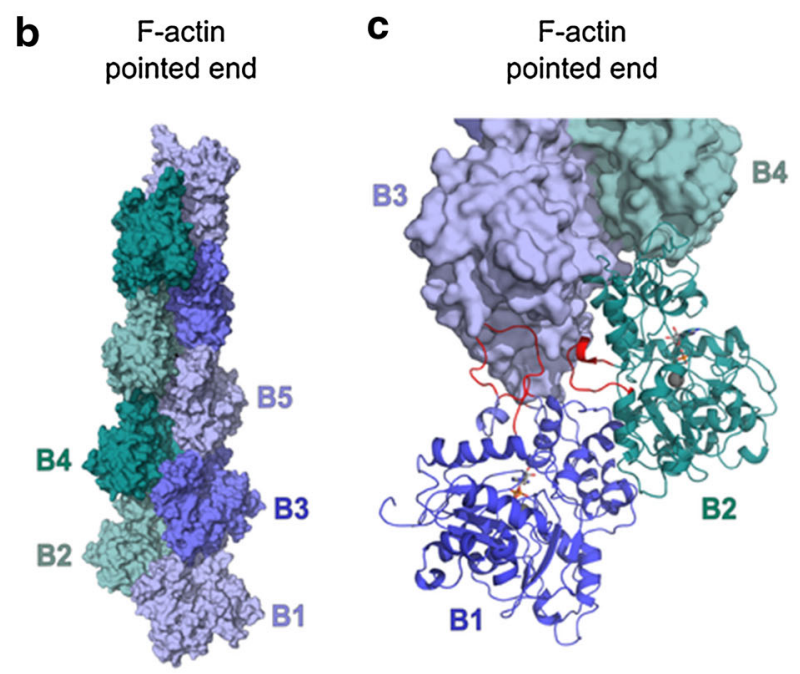

F-actin

barbed end
F-actin
barbed end

structure of a $167^{\circ}$ twisted F-actin nonamer (4A7N; [124]). The fast growing barbed end and slow growing pointed end are indicated. c Important longitudinal contacts between terminal F-actin subunits at the filament barbed end. The two terminal actin protomers B1 and B2 are depicted as cartoon. Loops involved in intermolecular binding are highlighted (red). The D-loop of actin B1 (aa 31-51) including its adjacent C-terminal region (aa 61-65) binds into the TBC of protomer B3. It also contributes to the transverse interaction between loop aa 265-271 of B2 with B3. The longitudinal contact of loop aa 243-245 of $\mathrm{B} 1$ with $\mathrm{B} 3$ is not visible in this representation [9, 123]

Amphipathic $\alpha$-helices of $\beta$-thymosins, WH2 domains, gelsolin, formins, twinfilin, capping protein $(\mathrm{CP})$, Eps8, RPEL motif of MAL proteins, etc. with 3-5 turns, irrespective of their polarity, dock in this pocket ([9], for review). The strength of binding of this $\alpha$-helix in itself does not strictly correlate with a defined function. To be specific, B-thymosins and RPEL motifs sequester G-actin and inhibit actin polymerization. In contrast, some $\mathrm{WH} 2$ domains bind G-actin as functional homologs of profilin, thus facilitating barbed end assembly. Gelsolin, CP, Eps8, twinfilin, Cytochalasin D and other macrolides cap barbed ends, while formins and some $\mathrm{WH} 2$ domains either cap or track barbed ends. Table 1 summarizes the structurefunction relationships and modes of action of these various regulators of barbed end assembly.

Most of these effectors have been characterized, using bulk solution assays and single filament assembly dynamics. Importantly, in cellular conditions, some barbed end regulators are soluble and free in the cytoplasm; others act in a membrane-bound state. The interplay between soluble and immobilized regulators of filament barbed end assembly drives the dynamic coupling between the actin cytoskeleton and membranes (or vesicles), and is pivotal in force production and shape definition. The functional competition between agonists and antagonists of barbed end growth raises structural and mechanistic issues. 
a

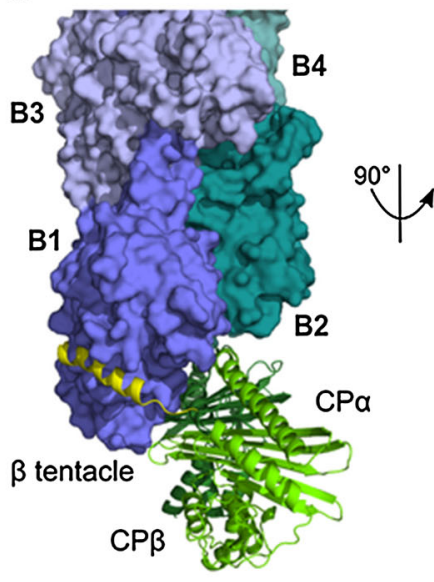

F-actin

barbed end

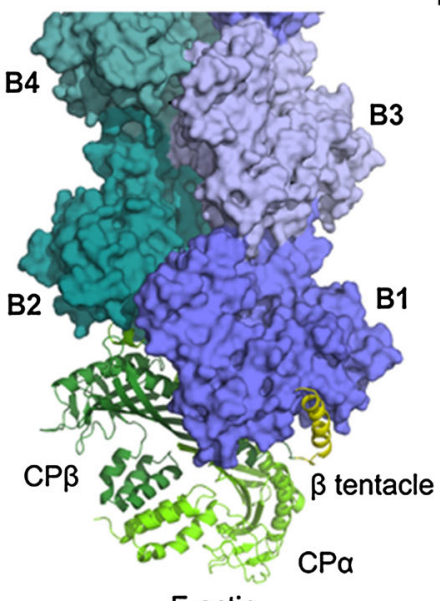

F-actin

barbed end b

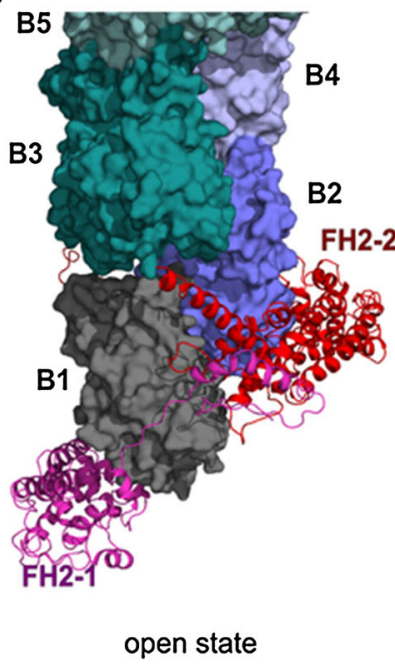

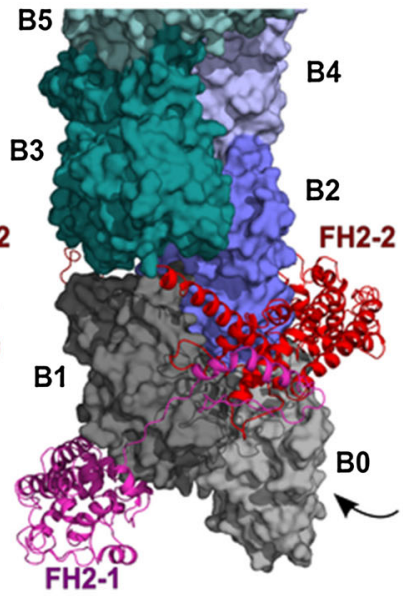

closed state
C

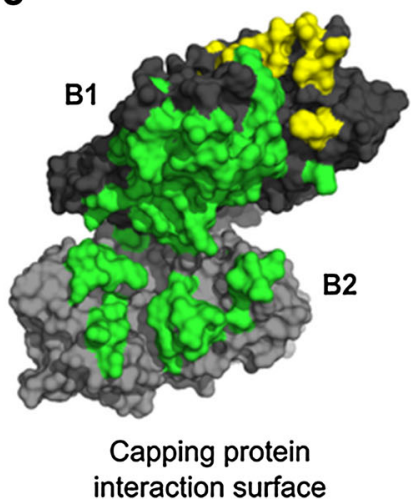

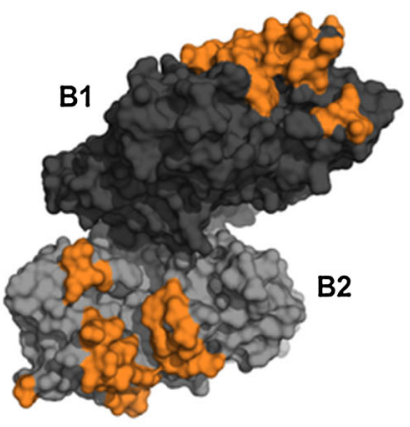

VopL WH2 1 interaction surface
Fig. 3 Structure of actin regulators bound to the barbed end. a Structure of CP bound to the barbed end. The $\alpha / \beta$ heterodimeric capping protein $(\mathrm{CP})$ is illustrated in ribbon diagrams $(\mathrm{CP} \alpha$ : light green; $\mathrm{CP} \beta$ : green; [43]; coordinates kindly provided by Y. Maeda). $\mathrm{CP} \alpha \beta$ forms strong electrostatic interactions at the interface of $\mathrm{B} 1$ and $\mathrm{B} 2$, while CP $\beta$ binds with its amphipathic $\beta$-tentacle ( $\beta \mathrm{T}$, yellow) to the hydrophobic TBC of B1. b Structure of a dimeric formin homology 2 (FH2) domain at the barbed end. The crystal structure of the $\mathrm{FH} 2$ domain of yeast formin Bnilp was crystallized encircling a flattened, $180^{\circ}$ twisted pseudo filament (1Y64; [54]). The Bni1-FH2/ G-actin structure was superimposed on actin B2 of the $167^{\circ}$ twisted F-actin barbed end (4A7N, shown in green-blue). The $180^{\circ}$ twisted protomers B1 and B0 are depicted in grey. The amphipathic $\alpha$-helix of the knob region of each FH2 hemidimer (chains FH2-1, FH2-2; magenta, red) binds to the $\mathrm{TBC}$ of $\mathrm{B} 1$ and $\mathrm{B} 2$, respectively. c Interaction surface of actin regulators at the barbed end. Highlighted

\section{Cytoplasmic soluble agonists and antagonists of filament barbed end assembly}

\section{Soluble agonists of polarized actin assembly: direct and indirect mechanisms}

The most important agonist of barbed end assembly is profilin. Profilin is a ubiquitous protein, present at

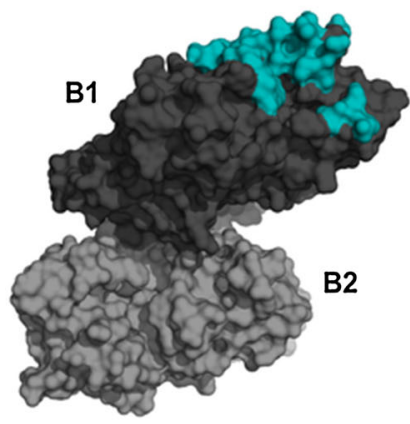

N-WASP WH2 1

interaction surface

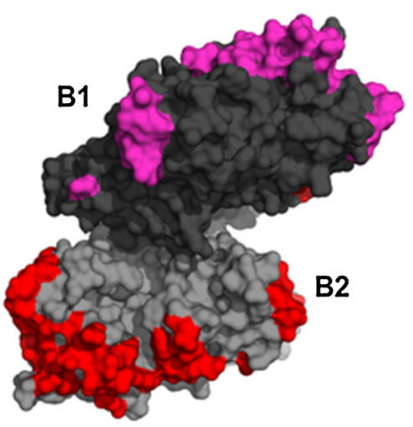

Bni1p FH2

interaction surface residues of B1 (dark grey) and B2 (grey) are involved in binding to the various regulators. Many barbed end binding proteins associate with an $\alpha$-helix (e.g. $\beta$-tentacle of CP, yellow surface) to the TBC of actin and additionally with other surface areas specific for each interaction. Surface coloring: residues of the barbed end involved in binding to $\mathrm{CP}(\mathrm{CP} \alpha \beta$ green, $\beta$-tentacle yellow $)$, VopL-WH2 1 (3M1F, orange, aa 130-151; [125]), N-WASP-WH2 1 (3M3N, blue, aa 397-418; [125]), or Bnilp-FH2 domain (1Y64, magenta, red; [54]). Since VopL dimerizes, the interacting residues of the first, $\mathrm{N}$-terminal WH2 domain of each VopL chain were highlighted on B1 and B2, respectively. The diagram suggests that two barbed end binding regulators can bind together to $\mathrm{B} 1$ and $\mathrm{B} 2$ pending some loss of binding strength, and use this transient ternary complex to displace each other. Examples include uncapping of CP by VopF [21] and by formin (Shekhar et al., submitted)

concentrations in the range of $10-100 \mu \mathrm{M}$ in cells. As a result of its binding to the barbed face of actin, it displays a dual interaction with G-actin and terminal subunits at filament barbed ends (Fig. 1b). The complex of profilin with ATP-G-actin supports filament growth at barbed ends exclusively with the same kinetic parameters as free G-actin [10]. Profilin-actin acts as an effective substrate of fast processive assembly catalyzed by formins [11-13]. 
Table 1 Regulators of actin filament barbed end dynamics and their specific mode of action

\begin{tabular}{|c|c|c|}
\hline Main activity & Regulator & Specific mode of function \\
\hline \multirow{10}{*}{$\begin{array}{l}\text { Participation in } \\
\text { barbed end } \\
\text { assembly }\end{array}$} & \multirow[t]{4}{*}{ Profilin } & Binds G-actin with high affinity \\
\hline & & Profilin-actin supports exclusively barbed end growth \\
\hline & & Profilin-actin is substrate for formins \\
\hline & & Binds barbed ends with low affinity and enhances disassembly \\
\hline & \multirow[t]{3}{*}{ WASP proteins (WH2) } & Catalyze filament branching with Arp2/3 complex \\
\hline & & Capture barbed ends via $\mathrm{WH} 2$ domain \\
\hline & & $\begin{array}{l}\text { Facilitate association of bound G-actin to barbed ends via } \mathrm{WH} 2 \\
\text { domain (profilin-like activity) }\end{array}$ \\
\hline & \multirow[t]{2}{*}{ Cordon-Bleu (WH2) } & Facilitates association of bound G-actin to barbed ends \\
\hline & & Nucleates and severs actin filaments \\
\hline & ADF/cofilin & $\begin{array}{l}\text { Increases depolymerisation of pointed ends, causing an increase in } \\
\text { pointed end critical concentration which in turn leads to enhanced } \\
\text { barbed end assembly at steady-state }\end{array}$ \\
\hline \multirow[t]{3}{*}{$\begin{array}{l}\text { Barbed end } \\
\text { tracking }\end{array}$} & Ena/VASP (WH2) & $\begin{array}{l}\text { Processively elongate F-actin barbed ends, promote dissociation of } \\
\text { barbed end assembly antagonists (uncapping) }\end{array}$ \\
\hline & VopF/VopL (WH2) & $\begin{array}{l}\text { Track F-actin barbed ends, promote dissociation of barbed end } \\
\text { assembly antagonists (uncapping) }\end{array}$ \\
\hline & Formins (FH1-FH2) & $\begin{array}{l}\text { Nucleate actin filaments, catalyse rapid processive BE assembly from } \\
\text { profilin-actin }\end{array}$ \\
\hline \multirow[t]{6}{*}{$\begin{array}{l}\text { Barbed end } \\
\text { capping }\end{array}$} & \multirow[t]{2}{*}{$\begin{array}{l}\text { Group I: Gelsolin, villin, brevin, severin, adseverin } \\
\quad\left(\text { very high affinity for barbed end, } K_{\mathrm{F}}=10^{-11} \mathrm{M}\right)\end{array}$} & $\begin{array}{l}\text { Prevent spontaneous nucleation and barbed end growth. Maintain a } \\
\text { large pool of unassembled actin }\end{array}$ \\
\hline & & Sever and cap filaments \\
\hline & $\begin{array}{l}\text { Group II: CP, Esp8, CapZ, twinfilin, IQGQP1, CapG } \\
\text { (lower affinity binding to barbed end, } \\
K_{\mathrm{F}}=10^{-9} \mathrm{M} \text { ) }\end{array}$ & $\begin{array}{l}\text { Prevent spontaneous nucleation and barbed end growth. Maintain a } \\
\text { large pool of unassembled actin }\end{array}$ \\
\hline & \multirow[t]{3}{*}{ Spire (WH2) } & Caps barbed ends weakly, preventing growth from profilin-actin \\
\hline & & Severs and caps filaments \\
\hline & & Recruits Formin 2 to actin filament barbed end \\
\hline
\end{tabular}

Notably, in binding to barbed end terminal subunits, profilin destabilizes actin-actin contacts and enhances the rate of actin dissociation from the barbed end [14, 15]. Profilin also competes with other barbed end binding proteins, in particular, it antagonizes capping proteins (Pernier et al., submitted).

WH2 domains are intrinsically disordered actin-binding modules that fold upon binding to actin, sharing the binding mode of $\beta$-thymosins. However, with a similar structural motif, they developed a large panoply of versatile functions different from $\beta$-thymosins. The WH2 domains in themselves are actin-binding blocks whose regulatory functions in actin assembly are governed by the electrostatic environment in which they bind actin [16]. Some WH2 domains behave as functional homologs of profilin, facilitating association of the bound actin to filament barbed ends: the WH2 domain of WASP proteins and the Cordon-Bleu protein, are known examples. Some WH2 domains facilitate nucleation by binding the actin monomer and neutralizing its negative charge, thus enhancing formation of prenuclei dimers. While tandem repeats of $\mathrm{WH} 2$ domains present in Spire, Cordon-Bleu or the pathogen effectors VopF and VopL display this nucleating function, a single WH2 domain of Cordon-Bleu, flanked by a lysinerich short extension, is sufficient to nucleate actin [17]. WH2 domains also may directly bind and track the terminal subunits at barbed ends, allowing association of G-actin and filament growth, in competition with other barbed end binding proteins. The WH2 domains of Spire cap barbed ends [18-20]; those of VopF or of Ena/VASP use their dimeric quaternary structure to track barbed ends and promote rapid dissociation of bound $\mathrm{CP}$, a reaction called "uncapping" [21].

$\mathrm{ADF} / \mathrm{cofilin}$ is another essential soluble regulator, which specifically binds ADP-bound G- and F-actin. Hence, it does not interact with ATP-bound growing filament barbed ends, yet it facilitates barbed end assembly in a paradoxical fashion, as follows: ADF/cofilin destabilizes filaments structurally and thermodynamically by weakening interactions between ADP-F-actin subunits. This results in a large increase in the intrinsic depolymerization rate constant of ADP-bound pointed ends, which promotes a large increase 
in the steady-state concentration of monomeric ATP-actin. This is confirmed by in vivo experimental evidence where higher concentration of monomers promotes faster polymerization at barbed ends ([22] for review).

\section{Soluble antagonists of filament barbed end assembly}

Barbed end capping proteins block barbed end assembly. They are generally cytoplasmic and act in soluble form, but might be immobilized in specific loci by regulatory ligands like CARMIL $[23,24]$. A large variety of capping proteins is found in living cells. They differ in their abundance, structure and strength of barbed end binding. Gelsolin and its related proteins (severin, adseverin, villin, brevin) bind extremely tightly to barbed ends, with binding constants of the order of $10^{-11} \mathrm{M}[25,26]$. Other cappers such as capping protein, the most ubiquitous and abundant one (about 1-2 $\mu \mathrm{M}$ in cells [27]), its muscle homolog CapZ, Eps8 [28], twinfilin [29], IQGAP1 [30], or $\mathrm{Ca}^{2+}$-dependent CapG which mimics a half-gelsolin molecule [31], display affinities lower than gelsolin i.e., binding constants to barbed ends in the subnanomolar to nanomolar range. Some WH2 repeat proteins such as Spire cap barbed ends with nanomolar affinity. An increasing body of evidence shows that capping proteins assist in maintaining a large enough pool of unassembled polymerizable actin monomers that is used locally and transiently for barbed end growth and protrusive force e.g., in lamellipodia or filopodia [32]. Capping proteins are also useful to block unnecessary filament nucleation in the cytoplasm. The balance between soluble cappers and membrane-immobilized nucleating factors thus maintains polarized actin assembly. This point is further developed in the next section.

\section{Filament turnover and barbed end nucleation and growth are chemically coupled}

The maintenance of a stationary concentration of monomeric polymerizable actin, which supports sustained local nucleation and polarized growth of filaments is made possible if a large enough fraction of the population of filament barbed ends are capped, thus setting the high concentration of monomeric actin imposed by pointed end dynamics [33]. The available monomeric actin can then be "funneled" towards the remaining non-capped filaments. Consistently, loss of CP slows down cell motility, while its overexpression enhances it $[3,34]$ and $\mathrm{CP}$ is required for cell migration [32].

Capping proteins thus act in synergy with actin depolymerizing factor, which causes an increase in the critical concentration at the pointed ends by enhancing the rate of pointed end disassembly. The resulting higher stationary concentration of actin monomers facilitates spontaneous nucleation. Spontaneously formed nuclei abort in the cytoplasm by their association with capping proteins, but are stabilized locally by association with membrane-bound nucleators (Fig. 4). Thus, in an apparent paradoxical fashion, agents that destabilize filaments and block barbed end growth in the cytoplasm actually facilitate locally stimulated creation of new filaments and faster barbed end growth of filaments at the individual level. These filaments grow for a short period of time, because $\mathrm{CP}$ eventually blocks their growth. These effects have been verified in vitro in reconstituted motility of $\mathrm{N}-\mathrm{WASP}$-coated and formin-coated beads, which both propel faster in the presence of a minimal amount of $\mathrm{CP}$ in the motility medium $[13,35]$. In vivo as well, the indirect effect of capping proteins on the growth of either free or formin-bound (or VASP-bound) barbed ends identically accounts for faster lamellipodia and filopodia extension in the presence of capping proteins. Consistently, slow filopodial dynamics are observed in CP-depleted cells [32]. Note that CP-depleted cells display an increased amount of F-actin because the imposed lower value of the critical concentration for filament assembly also imposes a lower amount of sequestered actin; nonetheless, these cells move slowly, indicating that the speed of actin-based movement does not increase with the amount of assembled actin, but with the stationary amount of polymerizable monomers.

Along the same line of logic, overexpression of soluble, constitutively active protein machineries that promote filament barbed end assembly, like the catalytic domain VCA of WASP proteins, or constitutively active formin fragments, should functionally antagonize capping proteins by imposing filament barbed end dynamics in the cytoplasm and causing a massive assembly of actin filaments similar to the phenotype of capping protein deletion. The resulting imposed lower concentration of polymerizable monomeric actin impairs migration and all motile processes. A different phenotype is generated by overexpressing the CA fragment of WASP proteins or any CA-related protein. These do not activate Arp2/3 complex but sequester it, hence they impose a lower limit of filament branching by insufficient amount of substrate. In conclusion, cells understand and use the intrinsic physico chemical aspects of actin self-assembly.

The rate of elongation in propulsive processes displays a bell-shaped dependence on $\mathrm{CP}$ concentration [35]. As discussed above, an increase in CP increases the rate of growth of uncapped ends. However, excess of CP blocks growth at all barbed ends, slowing down actin-based motile processes, eventually abolishing treadmilling.

Direct competition for barbed ends takes place between soluble CP and other barbed-end binding proteins like membrane-activated formins. This competition, which 


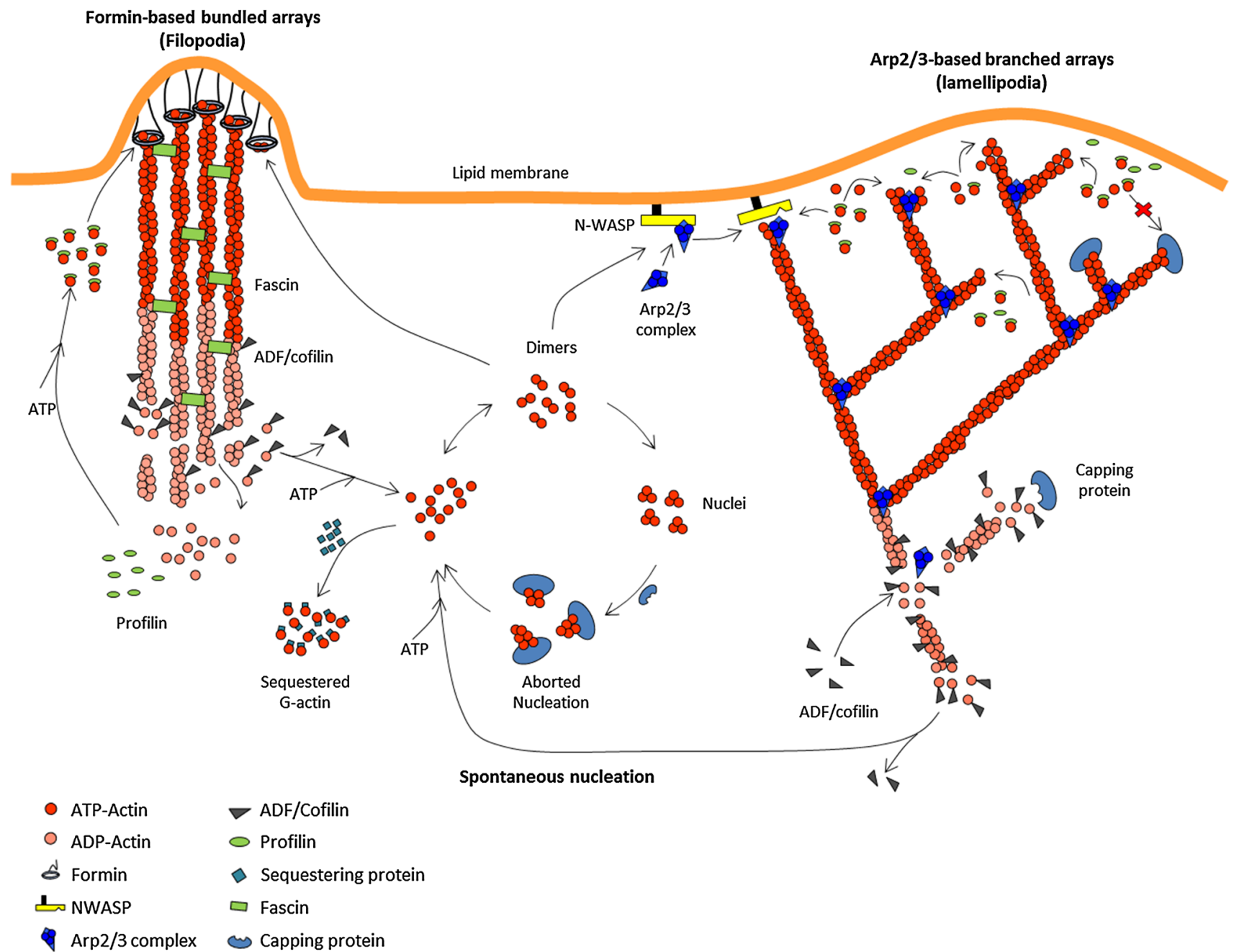

Fig. 4 Sketch of the regulation of filament assembly in motile processes. Regulated treadmilling drives both site-directed barbed end nucleation and polarized assembly. For simplicity, only the protein machineries responsible for filament branching (WASP family proteins) and for processive individual filament assemblies (formins) are drawn. Filament tracking by Ena/VASP and other WH2 domain proteins are conceptually similar, and not shown for simplicity. In the generalized treadmilling cycle, polymerizable ATP-bound actin monomers are produced by depolymerization of ADP-actin from filament ADP-bound pointed ends, facilitated by ADF/cofilin. Note that an excess of ADF will block monomers in the ADF-ADP-bound non-motile state (no treadmilling), because nucleotide exchange is

develops through so far unexplored mechanisms, is important in regulating the number of formin-initiated filaments in filopodial bundles, and the length and morphology of these bundles. The presence of a punctate pattern of $\mathrm{CP}$ along the filopodia and the rod-like appearance of filopodia in CP-depleted cells, contrasting with the tapered shape of filopodia in control cells [32], altogether testify that $\mathrm{CP}$ regulates not only the rate of extension of filopodia, but also the number of formin-attached filament barbed ends at the tip of filopodia. inhibited by ADF. Thus, the effect of ADF on motility presents a bell shape dependence on concentration. Spontaneous nucleation by ATPactin is aborted in cytoplasm by capping protein, and locally facilitated by nucleators. Formin-induced nucleation requires actin dimers. The sketch implicitly assumes that an actin dimer/trimer prenucleus can as well undergo branching with WASP and Arp2/3 complex. Capping protein arrests filament growth in dendritic filament arrays. A balanced number of filament barbed ends is maintained via the equal frequency of "birth" by branching and "death" by capping. Capping protein is also required for regulating the length of formin-induced filament in filopodia

The interplay between cappers and positive regulators of barbed end growth has drastic effects when the extent of barbed end capping varies within the narrow range of 95-100 \%, in which a large change develops in the steadystate concentration of both polymerizable monomeric actin and sequestered (unpolymerizable) actin [7, 33, 36-38]. In other words, uncapping of only a few percent of filaments elicits massive effects on motility based on actin assembly. The predominant mass of soluble $\mathrm{CP}$ blocking barbed ends in the bulk cytoplasm ensures the establishment of a high 
monomer concentration required for local efficient barbed end growth of the transiently non-capped barbed ends, in lamellipodia or filopodia. Noteworthily, proteins harboring uncapping CPI motifs [27] like CARMIL, CIN85/CD2AP, FAM21, CAP-ZIP are all conspicuously associated with WASP protein-Arp2/3 mediated branched filament arrays. These regulators of $\mathrm{CP}$ dynamics at filament barbed ends localize at specific membrane-bound sites, ensuring localized effects on the dynamics and morphology of dendritic arrays of actin filaments.

As discussed earlier [39], de novo assembly of filaments from the pool of sequestered actin takes place as a relaxation process from one steady-state level to another one, upon a stimulus-induced change in reactivity of the barbed ends. The time dependent lowering of the steadystate free G-actin concentration is simultaneously amplified in mass by sequesterers, causing an increase in mass of F-actin equal to the decrease in mass of sequestered actin.

In conclusion, the regulation of barbed end capping, both in the bulk cytoplasm and at specific loci, is of crucial importance in motility.

\section{Interplay at barbed ends: mutually exclusive or non-competitive binding and "uncapping"}

As briefly outlined in the introduction, if two regulators share only partial binding subsites on terminal subunits, they may bind the barbed end simultaneously, thus increasing the structural and functional complexity. Transient binding of the two proteins together may also facilitate and lead to the dissociation of one of them by the other. Typical physiologically relevant cases concern the regulation of the dwell time at barbed ends of proteins that by themselves dissociate very slowly, like $\mathrm{CP}$ and formins.

\section{Mechanisms of uncapping of CP}

$\mathrm{CP}$ binds barbed ends with high affinity $(\mathrm{Kd}=0.1 \mathrm{nM})$ and by itself dissociates from barbed ends with a half-time of about $30 \mathrm{~min}$ [40]. Both the abundance of CP and its extremely slow dissociation call for a regulation of its activity. This regulation is implemented either by controlling the availability of free CP or by enhancing its dissociation. Myotrophin V1 and CARMIL are two known regulators of $\mathrm{CP}$ that employ these mechanisms. Myotrophin simply sequesters free $\mathrm{CP}$ while CARMIL and proteins of the CapZIP family, which harbor a consensus CPI (capping protein interaction) motif, actually "uncap" CP from barbed ends via formation of a transient barbed end-bound CP-CARMIL complex ([24, 27, 41] for review).
Uncapping of $\mathrm{CP}$ was also shown to be mediated by dimerized WH2 domains, present in VopF/VopL or in Ena/ VASP proteins. The Vibrio cholerae/Vibrio parahaemolyticus outer proteins VopF/VopL harbor a unique organization in dimers of three $\mathrm{WH} 2$ repeats. This feature is responsible for their ability to uncap actin filaments from barbed end-bound capping protein [21]. The barbed face of the terminal subunit of CP-capped barbed ends is occupied by the $\beta$-tentacle of $\mathrm{CP}[42,43]$ (Fig. 3a, c) leaving the WH2-binding site largely available on the penultimate subunit. Therefore, $\operatorname{VopF}(\mathrm{V})$ and $\mathrm{CP}(\mathrm{C})$ can bind together to filament barbed ends (B), causing reduced affinity of both ligands, in a ternary complex BVC. Stabilization of $\mathrm{VopF}$ at barbed ends is provided by weak interactions of the C-terminal dimerization domain with the filament side. Rapid dissociation of CP from the transient BVC complex allows VopF to potentially track filament barbed ends in the BV state, possibly via alternate interactions of $\mathrm{WH} 2$ domains from opposite protomers with barbed end terminal subunits. Importantly, only $10 \%$ uncapping has massive effects on barbed end reactivity [38]. VopF was proposed as a model for proteins of the Ena/VASP family, which consist of tetramerized WH2 domains adjacent to an F-actin-binding domain, and may track barbed ends using the same mechanism [44].

\section{Interplay of spire and formin 2 at barbed ends}

Two other barbed end binding proteins, formin 2 and the four-WH2 repeat containing protein Spire, together regulate barbed ends in cytoplasmic actin assembly in asymmetric meiotic cell division. As compared to other formin FH1FH2 domains, formin 2 by itself nucleates poorly in the presence of profilin-actin and binds extremely slowly to barbed ends. Spire, on its own, caps barbed ends via its WH2 domains. Via association of its KIND domain with the C-terminal region (tail) of formin 2, Spire rapidly recruits formin 2 to the barbed end. This local interaction leads to rapid displacement of Spire by formin 2 at the barbed ends and onset of fast processive assembly [20] by formin 2. In other words, Spire behaves as an activator of the Rho-independent formin 2. This "kick-off" mechanism implies that binding of formin 2 to some of its available binding subsites at barbed ends weakens the binding of the $\mathrm{WH} 2$ domains of Spire, facilitating their competitive displacement by the homolog binding elements of formin 2 . This mechanism is at the origin of the synergy between formin 2 (Cappuccino in Drosophila) and spire in mediating the massive assembly of cytoplasmic actin networks, which is required for spindle translocation to the cortex in mammalian asymmetric meiotic division, and for axis patterning at mid-oogenesis of Drosophila [45-47]. 


\section{Interplay of CP and formins at barbed ends}

Formins and $\mathrm{CP}$ are considered as strict competitors for barbed end binding with formins "protecting" the barbed ends from CP ([27, 48] for review). However, CP caps formin-bound barbed ends, pending a greatly reduced affinity of CP [13], in the process causing rapid arrest of formin-mediated motile processes. Gelsolin also arrests the movement of formin coated beads and poisons them, consistent with formation of a stable complex at the bead surface between formin, actin and gelsolin [13]. The effects on barbed end dynamics which result from the transient association of both $\mathrm{CP}$ and formin at the same barbed end have bearings in the regulation of formin-mediated fast processive growth of filaments in vivo, and are being explored in full detail (Shekhar et al., submitted).

\section{Establishment and maintenance of polarity in actin assembly}

Establishment and maintenance of polarized growth of filaments relies on transient or permanent links between the barbed ends of growing filaments and the membrane. As illustrated in Fig. 4, filament barbed ends appear to terminate at a membrane in lamellipodia protrusion, filopodia extension, focal adhesions and podosomes, endosomal fission and in pathogen propulsion. A large variety of "nucleators" of polarized actin assembly are at work in each of these processes. The links between the actin filament barbed ends and the membrane are thus structurally and temporally different in each of these individual cases that generally fall in the class of "site-directed barbed end assembly". Using various molecular mechanisms, the interaction of the immobilized assembling machinery with the filament barbed ends allows filament growth from G-actin or profilin-actin, as well as the binding of competing soluble regulators like capping proteins. Sitedirected barbed end assembly is thus controlled in a signalresponsive fashion at the membrane. Recent data indicate that the curvature of the membrane, linked to its lipid composition and association with BAR domain containing proteins, adds further complexity to the structure-function relationship at work in various shape changes [49-51].

\section{Formins as catalysts of insertional actin assembly}

Formins are dimeric proteins that both nucleate actin assembly and catalyze rapid processive assembly of actin filaments. Formin-bound barbed ends elongate between 3and 10-fold faster than unliganded barbed ends, and the formin often remains bound to the elongating barbed end for several minutes $[12,13]$. Although the essential actin- binding moiety is the Formin Homology 2 (FH2) head-totail ring shaped dimer, the Formin Homology 1 (FH1) proline rich stretch binds profilin, which is required for the biological function of most formins. In vitro, profilin is required for fast processive barbed end assembly of filaments by formins. Hence, profilin-actin is the actual substrate of formin. The isolated $\mathrm{FH} 2$ ring structure in itself encircles barbed end terminal subunits in a conformation called the "closed" state, that either slows down or blocks barbed end growth (Fig. 3b, c) ([52-54], for review). Nucleation is facilitated energetically by stabilization of prenuclei actin dimers by the $\mathrm{FH} 2$ domain [55]. The additional association of the FH1 domain with profilin allows FH1-FH2 to bypass inhibition of nucleation by profilin and catalyze rapid processive assembly from profilin-actin [12, 13] (Fig. 4). The detailed structural changes at the forminF-actin interface and related changes in binding strength of formin accompanying their tracking of growing barbed ends are not known ([52] for review). Actual rotation of formin around the elongating filament has been reported [56]. Formins indirectly cooperate with $\mathrm{ADF} /$ cofilin and cappers, which together increase the stationary pool of profilin-actin, used by formin in catalytic processive assembly [13].

Formins generally are activated by signaling molecules at membranes to promote insertional processive assembly. The available space between barbed ends and the membrane is potentially regulated chemically and mechanically, as described below.

\section{Formins are mechanosensitive machines}

Due to their attachment to membranes, formins are able to sense and to react to forces coming from membrane tension, and they can apply a pulling force on elongating actin filaments. Quantitative measurements indicate that piconewton pulling forces applied by a microflow to a formin-bound filament accelerate the rate of processive assembly, and slow down processive disassembly [57]. These results have demonstrated that formins are mechanosensitive, and traction forces affect the biochemical cycle of formin tracking barbed ends. During the cycle of processive assembly, the $\mathrm{FH} 2$ domains of each protomer of the formin dimer are thought to alternate between a "closed", strongly barbed end-bound state and an "open", less strongly bound state [52, 54]. Consistently, pulling on barbed end-bound formins favors the "open" state of the FH2 domain in which weakened binding allows association of G-actin to the barbed end. In turn, slower disassembly under force reflects the lower percent of time spent by formin in the closed state in which disassembly is favored. Formins work under tension in many motile processes in vivo. For instance, in cytokinesis, formins initiate 
assembly of actin bundles at nodes, and have to work under traction forces exerted by myosin during closure of the cytokinetic ring. Formins may also work against compressive forces coming from membrane tension in protrusive or adhesive structures.

\section{Regulation of the length of formin-assembled filaments}

The slow dissociation of formins from the barbed end during processive assembly can lead, even in the presence of a low concentration of profilin-actin $(0.1 \mu \mathrm{M})$, to filaments of up to $20 \mu \mathrm{m}$ in length before filament detachment from formin occurs. In bundles of filaments initiated by clustered formins, a fraction of formins remains bound to the bundle at any given time, increasing the period of time spent by the bundle in the attached state and the resulting bundle length. In vivo, however, the length of filopodia or of the actin filaments that compose the cytokinetic ring appears to reach only a limited length, suggesting that some down-regulation of processive assembly occurs. Bud14 has been identified as such a displacement factor that kicks off yeast formin Bnr1 from the barbed end [58]. Further association of Bud14 with Kelch proteins, homologs of fission yeast proteins tea1p and tea3p, regulates the length of formin-induced actin bundles in a large number of processes [59].

Similarly, capping proteins [13] and Cytochalasin D [60] rapidly displace formins from the barbed ends, causing detachment of actin bundles from formin-beads or aggregates. This result contrasts with the conventional view according to which formins "protect" barbed ends from their blockage by cappers. The structural details of the catalytic step at which displacement of formin by capping protein may be facilitated and the possible role of ATP hydrolysis are not yet known.

\section{WASP family proteins as membrane-bound catalysts of filament branching}

Among the site-directed nucleators of filaments, the WASP family proteins (Table 2) are particularly interesting. These proteins are widespread and all catalyze the same reaction i.e., filament branching with Arp $2 / 3$ complex, in various cellular processes.

SCAR/WAVE proteins generate branched filament arrays to promote extension of lamellipodia [1] as well as cortical actin re-assembly in blebs [61] and many other developmental processes and synaptogenesis [62, 63]; $\mathrm{N}-\mathrm{WASP}$ based branching is involved in formation of invadopodia and podosomes, internalization of endocytic vesicle [64-66], formation of dendritic spines [67, 68] and formation of cell-cell junctions mediated by cadherin [6972]; WASH-induced filament branched arrays promote scission of tubular membranes in vesicular trafficking [73, 74]; WHAMM/JMY drives Golgi reorganization [75, 76] and DIP/WISH/SPIN90 proteins act in endocytosis and lamellipodia [77-79]. In these functions, WASP proteins all localize at membranes where they are activated and regulated by different mechanisms ([80-83], for reviews).

Central to the mechanism of force production is the catalysis of filament branching. Activation of WASP proteins always results in exposure of the $\mathrm{C}$-terminal catalytic domain, called VCA or WCA. This domain consists of a WH2 motif (in one or two repeats), C (connector) and A (acidic) regions stand adjacent to each other in the sequence of most WASP proteins except WASH in which 100 residues separate $C$ from A [83]. Incidentally, the Listeria ActA protein, which catalyzes filament branching

Table 2 WASP family proteins and related regulators

\begin{tabular}{|c|c|c|c|c|}
\hline Proteins & In vivo functions & Cellular localization & Regulators & References \\
\hline N-WASP & $\begin{array}{l}\text { Formation of invadopodia and podosomes, internalization of } \\
\text { endocytic vesicle }\end{array}$ & Filopodia & $\mathrm{Cdc} 42, \mathrm{PIP} 2$ & {$[64-66]$} \\
\hline WASH & Scission of tubular membranes in vesicular trafficking & Endosome & PIP3 & {$[73,74]$} \\
\hline $\begin{array}{l}\text { WHAMM/ } \\
\text { JMY }\end{array}$ & Drive Golgi reorganization & $\begin{array}{l}\text { Golgi membrane, perinuclear } \\
\text { region } \\
\text { Brain tissue, neuronal cells }\end{array}$ & - & {$[75,76]$} \\
\hline SCAR/WAVE & Extension of lamellipodia & Lamellipodia & PIP3, IRSp53 & {$[1]$} \\
\hline WAFL & Endocytosis, formation of filopodia & Early Endosome & - & {$[119,121]$} \\
\hline $\begin{array}{l}\text { DIP/WISH/ } \\
\text { SPIN90 }\end{array}$ & Endocytosis, formation of lamellipodia & Lamellipodia & $\begin{array}{l}\text { Cdc42, RhoA, } \\
\text { Rac1 }\end{array}$ & {$[77-79]$} \\
\hline $\begin{array}{l}\text { RickA } \\
\quad(\text { Rickettsia })\end{array}$ & Infection of cell, use the actin-based motility system & Cytoplasm & - & {$[118,120]$} \\
\hline ActA (Listeria) & Infection of cell, use the actin-based motility system & Cytoplasm & - & {$[84,85]$} \\
\hline
\end{tabular}


responsible for Listeria propulsion in the host cytoplasm, harbors motifs structurally and functionally analogous to the $\mathrm{WH} 2, \mathrm{C}$ and A motifs of WASP proteins, but in different order in the sequence $[84,85]$.

At each catalytic cycle of filament branching, one molecule of Arp $2 / 3$ is incorporated at a branch junction from which a "daughter" filament is initiated (Fig. 4). Fluorescence imaging of the branched filament array reveals that filaments are created by branching at the very tip of the lamellipodium, and Arp2/3 and actin treadmill at identical rates through the meshwork [3], while WASP undergoes slow turnover at the membrane [86]. Reconstituted motility assays similarly show that Arp2/3 and actin are incorporated at the same rate into the dendritic meshwork growing from the bead at which N-WASP is immobilized [35]. When vesicles are functionalized with $\mathrm{N}-\mathrm{WASP}$, co-segregation of actin and N-WASP takes place during propulsion [87]. In conclusion, filament growth and site-directed branching are kinetically coupled reactions. Branching creates a transient link between individual actin filaments and the membrane, following which the filament barbed ends grow transiently, developing a pushing force while keeping their barbed ends oriented toward the membrane (Fig. 4). At the macroscopic level of the dendritic meshwork, this mechanism is equivalent to processive assembly, since branching maintains a fraction of the newly formed filaments attached during assembly of the network, as described in the tethered ratchet model [88]. Delayed barbed end capping, debranching and pointed end disassembly, together maintain the stationary morphology of the array.

The general topology, high resolution structure and dynamics of the large macromolecular complex formed at the membrane between a filament, WASP and Arp2/3 in the catalysis of branching represent a major challenge for future research.

\section{Kinetic analysis of assembly of branched filaments in solution}

The isolated VCA has been extensively used to analyze filament branching both in bulk solution and in single filament TIRF microscopy assays. Polymerization of actin in the presence of VCA and Arp2/3 complex shows constant acceleration due to autocatalytic multiplication of growing filaments by branching. Addition of pre-assembled filaments at time zero shortens the initial acceleration period, in a manner dependent on the number of barbed ends rather than on the mass of added F-actin. This feature is suggestive of barbed end branching by Arp2/3. It is further consistent with the measured length correlation of mother and daughter filaments [7]; Contradictory data, obtained using capped filaments to stimulate branching, leave open the issue of filament side versus barbed end branching $[84,89]$.

TIRF microscopy was used to visualize live assembly and branching of single filaments anchored by myosin or maintained in close proximity of the glass surface [90]. In this 2D geometry, branches emerge from the sides of filaments, and events compatible with side and end branching are seen as well [91, 92]. Side-branching appeared favored on the convex face of curved filaments [93]. High resolution single molecule imaging and quantitative analysis of branching by VCA and Arp $2 / 3$ complex show that binding of $\operatorname{Arp} 2 / 3$ to filament sides is slow, association is two- to fourfold faster with VCA, although quite slow $\left(\mathrm{k}+=0.025 \mu \mathrm{M}^{-1} \mathrm{~s}^{-1}\right.$ per F-actin subunit); growth of a daughter branch occurs extremely infrequently, from only $1 \%$ of the filament-bound Arp2/3 [94], and is kinetically limited by dissociation of VCA [95]. The remarkably low efficiency of side-branching in 2D microscopy assays contrasts with the densely branched actin meshwork observed in lamellipodia, in actin tails of pathogens and in 3D bulk solution polymerization assays.

\section{Biochemical and structural analysis of complexes of Arp2/3 with VCA, monomeric actin and actin filaments}

Biochemical and structural analysis of the interactions between VCA, actin and Arp2/3 complex is at the heart of the possible mechanisms of filament branching. Binding of Arp $2 / 3$ to VCA induces a structural change in Arp $2 / 3$ complex that strengthens binding of ATP to Arp2 [96]. The Arp2 subunit is essential for filament branching by VCAArp2/3 [97, 98]. The WH2 domain (V) of VCA, even in absence of Arp2/3, binds G-actin in a complex that participates in filament barbed end assembly like profilinactin $[99,100]$. Via its WH2 domain VCA also captures filament barbed ends [101] and elicits rapid processive barbed end assembly [102]. The entire CA region interacts with Arp2/3 complex. Various structural studies of the branching complex and the filament branch junction so far fail to provide a comprehensive view of the interface between Arp $2 / 3$ and VCA, and the position of all subunits at the branch junction [103-106].

The VCA-actin-Arp2/3 complex, considered as the "branching complex" that interacts with the mother filament [107], displays a 1:1:1 stoichiometry in gel filtration [108]. A second VCA low affinity binding site $(\mathrm{Kd}=1.6 \mu \mathrm{M})$ was detected on Arp2/3 complex [109, 110]. Its putative role in branching is hard to reconcile with the nanomolar range of efficiency of VCA and the fact that efficient propulsion of N-WASP functionalized particles is recorded when the N-WASP molecules are at a distance of $20 \mathrm{~nm}$ [35]. The limited information addressing how Arp2/ 
3 complex branches filaments is an obstacle to understanding how regulators like CK666 [111] and glia maturation factor (GMF, a debranching factor of the ADF/cofilin family, [112]) act.

Technical difficulties that have slowed our progress include the limited available resolution in the structures of large macromolecular complexes, the limited available amounts of native and recombinant genetically modified Arp2/3 complex, and the 2D constraints imposed by TIRF microscopy in monitoring formation of the 3D structure of branched filaments. Due to these difficulties, the proposed models are dominated by assumptions made ab initio on structural changes in the organization of the Arp2/3 complex during branching.

\section{In vivo analysis of dendritic meshworks}

The high density of the intricate array of branched filaments in the actin tail of propelling pathogens precludes the accurate tracking of individual filaments in electron micrographs $[113,114]$. This limitation was overcome using the baculovirus, which propels by site-directed assembly of a small number of individually identified branched filaments [115]. The virus appears to move at a few $\mu \mathrm{m} / \mathrm{min}$ using only a dozen of pushing filaments that are branched at the virus surface. The barbed ends of the individual newly assembled filaments are seen bound to the virus surface. Very similar EM observations have been made on $50 \mathrm{~nm}$ ActA-coated beads placed in cell extracts [6].

\section{Coordination between the turnover of WASP-Arp2/3 promoted branched filament arrays and formin- induced bundles that co-exist in cell processes}

Assuming that a pool of polymerizable actin monomers is established and feeds site-directed barbed end elongation, an unsolved issue concerns the seemingly homogeneous rate of protrusion and filament turnover in the lamellipodia, where both dendritic filament arrays and formin-mediated filopodia and microspikes co-exist [116]. Formins are expected, under this condition, to mediate about five- to tenfold faster actin assembly than the free barbed ends. Yet the turnover of actin filaments appears maintained at the same value within all these structures, generating a smooth leading edge. A possible explanation is that the mechanical rigidity of the membrane imposes a load that regulates barbed end growth in lamellipodia. In contrast, dendritic filament arrays and filopodia segregate in dendritic spines and mediate different rates of protrusion [67], which may indicate that the tension of the membrane in these cellular extensions is lower, enabling more dynamic changes in shape.

\section{Conclusions and perspectives}

The control of actin filament barbed end dynamics is mediated by a large number of soluble as well as membranebound effectors, which may act either directly by binding barbed ends, or indirectly by affecting the on flux of actin monomers at barbed ends.

Effectors that bind barbed ends may either exclude each other or bind in synergy together at the barbed ends, or may displace each other from the barbed end via formation of transient ternary complexes. The binding of regulatory proteins may further be affected by the state of the nucleotide bound to actin subunits at the barbed end. Many of these processes also include irreversible ATP hydrolysis. Elucidating such complex binding schemes, will require more extensive biochemical, kinetic, as well as structural studies.

High resolution electron microscopy of complexes formed at the barbed ends is anticipated to foster our progress. Rapid kinetics of the changes in reactivity of filament barbed ends using microfluidics-assisted TIRF microscopy of individual filaments, in assembly and disassembly regimes and presence of various regulatory ligands, is clearly an avenue for mechanistic studies.

Because most of the regulation of polarized filament assembly is mediated by regulators that are bound both to membranes and to filament barbed ends, the chirality of the growing helical filament plays an important role. A consequence of the chirality of the actin filament is revealed at high scale in the chiral organization of cytoskeletal patterns of radial and transverse fibers in fibroblasts constrained to a circular shape [117]. Future force-based approaches of the bearings of this intrinsic property of actin in morphogenetic processes include the application of controlled membrane tension and torque to the growing helical filament. New experiments will have to be designed to address these issues.

Acknowledgments MFC acknowledges funding from ERC (advanced grant "Forcefulactin" 2010-2015 \# 249982) and from EU FP7 (MitoSys consortium \# 2415648).

Open Access This article is distributed under the terms of the Creative Commons Attribution 4.0 International License (http:// creativecommons.org/licenses/by/4.0/), which permits unrestricted use, distribution, and reproduction in any medium, provided you give appropriate credit to the original author(s) and the source, provide a link to the Creative Commons license, and indicate if changes were made.

\section{References}

1. Pollard TD, Borisy GG (2003) Cellular motility driven by assembly and disassembly of actin filaments. Cell 112(4): 453-465 (pii: S009286740300120X) 
2. Welch MD, Way M (2013) Arp2/3-mediated actin-based motility: a tail of pathogen abuse. Cell Host Microbe 14(3):242-255. doi:10.1016/j.chom.2013.08.011

3. Iwasa JH, Mullins RD (2007) Spatial and temporal relationships between actin-filament nucleation, capping, and disassembly. Curr Biol 17(5):395-406. doi:10.1016/j.cub.2007.02.012

4. Lai FP, Szczodrak M, Block J, Faix J, Breitsprecher D, Mannherz HG, Stradal TE, Dunn GA, Small JV, Rottner K (2008) Arp2/3 complex interactions and actin network turnover in lamellipodia. EMBO J 27(7):982-992. doi:10.1038/emboj.2008.34

5. Bugyi B, Carlier MF (2010) Control of actin filament treadmilling in cell motility. Annu Rev Biophys 39:449-470. doi:10. 1146/annurev-biophys-051309-103849

6. Cameron LA, Svitkina TM, Vignjevic D, Theriot JA, Borisy GG (2001) Dendritic organization of actin comet tails. Curr Biol 11(2):130-135 (pii: S0960-9822(01)00022-7)

7. Pantaloni D, Boujemaa R, Didry D, Gounon P, Carlier MF (2000) The Arp2/3 complex branches filament barbed ends: functional antagonism with capping proteins. Nat Cell Biol 2(7):385-391. doi:10.1038/35017011

8. Galkin VE, Orlova A, Schroder GF, Egelman EH (2010) Structural polymorphism in F-actin. Nat Struct Mol Biol 17(11):1318-1323. doi:10.1038/nsmb.1930

9. Dominguez R, Holmes KC (2011) Actin structure and function. Annu Rev Biophys 40:169-186. doi:10.1146/annurev-biophys042910-155359

10. Pollard TD, Cooper JA (1984) Quantitative analysis of the effect of Acanthamoeba profilin on actin filament nucleation and elongation. Biochemistry 23(26):6631-6641

11. Kovar DR, Harris ES, Mahaffy R, Higgs HN, Pollard TD (2006) Control of the assembly of ATP- and ADP-actin by formins and profilin. Cell 124(2):423-435. doi:10.1016/j.cell. 2005.11.038

12. Kovar DR, Kuhn JR, Tichy AL, Pollard TD (2003) The fission yeast cytokinesis formin $\mathrm{Cdc12} p$ is a barbed end actin filament capping protein gated by profilin. J Cell Biol 161(5):875-887. doi:10.1083/jcb.200211078

13. Romero S, Le Clainche C, Didry D, Egile C, Pantaloni D, Carlier MF (2004) Formin is a processive motor that requires profilin to accelerate actin assembly and associated ATP hydrolysis. Cell 119(3):419-429. doi:10.1016/j.cell.2004.09.039

14. Bubb MR, Yarmola EG, Gibson BG, Southwick FS (2003) Depolymerization of actin filaments by profilin. Effects of profilin on capping protein function. J Biol Chem 278(27): 24629-24635. doi:10.1074/jbc.M302796200

15. Jegou A, Niedermayer T, Orban J, Didry D, Lipowsky R, Carlier MF, Romet-Lemonne G (2011) Individual actin filaments in a microfluidic flow reveal the mechanism of ATP hydrolysis and give insight into the properties of profilin. PLoS Biol 9(9):e1001161. doi:10.1371/journal.pbio.1001161

16. Carlier MF, Pernier J, Avvaru BS (2013) Control of actin filament dynamics at barbed ends by $\mathrm{WH} 2$ domains: from capping to permissive and processive assembly. Cytoskeleton (Hoboken) 70(10):540-549. doi:10.1002/cm.21124

17. Husson C, Renault L, Didry D, Pantaloni D, Carlier MF (2011) Cordon-Bleu uses $\mathrm{WH} 2$ domains as multifunctional dynamizers of actin filament assembly. Mol Cell 43(3):464-477. doi:10. 1016/j.molcel.2011.07.010

18. Bosch M, Le KH, Bugyi B, Correia JJ, Renault L, Carlier MF (2007) Analysis of the function of Spire in actin assembly and its synergy with formin and profilin. Mol Cell 28(4):555-568. doi:10.1016/j.molcel.2007.09.018

19. Ito T, Narita A, Hirayama T, Taki M, Iyoshi S, Yamamoto Y, Maeda Y, Oda T (2011) Human spire interacts with the barbed end of the actin filament. J Mol Biol 408(1):18-25. doi:10.1016/ j.jmb.2010.12.045
20. Montaville P, Jegou A, Pernier J, Compper C, Guichard B, Mogessie B, Schuh M, Romet-Lemonne G, Carlier MF (2014) Spire and Formin 2 synergize and antagonize in regulating actin assembly in meiosis by a ping-pong mechanism. PLoS Biol 12(2):e1001795. doi:10.1371/journal.pbio.1001795

21. Pernier J, Orban J, Avvaru BS, Jegou A, Romet-Lemonne G, Guichard B, Carlier MF (2013) Dimeric WH2 domains in Vibrio VopF promote actin filament barbed-end uncapping and assisted elongation. Nat Struct Mol Biol 20(9):1069-1076. doi:10.1038/ nsmb. 2639

22. Carlier MF, Ressad F, Pantaloni D (1999) Control of actin dynamics in cell motility. Role of ADF/cofilin. J Biol Chem 274(48):33827-33830

23. Fujiwara I, Remmert K, Hammer JA 3rd (2010) Direct observation of the uncapping of capping protein-capped actin filaments by CARMIL homology domain 3. J Biol Chem 285(4):2707-2720. doi:10.1074/jbc.M109.031203

24. Fujiwara I, Remmert K, Piszczek G, Hammer JA (2014) Capping protein regulatory cycle driven by CARMIL and V-1 may promote actin network assembly at protruding edges. Proc Natl Acad Sci USA 111(19):E1970-E1979. doi:10.1073/pnas.1313738111

25. Silacci P, Mazzolai L, Gauci C, Stergiopulos N, Yin HL, Hayoz D (2004) Gelsolin superfamily proteins: key regulators of cellular functions. Cell Mol Life Sci 61(19-20):2614-2623. doi:10. 1007/s00018-004-4225-6

26. Stossel TP, Chaponnier C, Ezzell RM, Hartwig JH, Janmey PA, Kwiatkowski DJ, Lind SE, Smith DB, Southwick FS, Yin HL et al (1985) Nonmuscle actin-binding proteins. Annu Rev Cell Biol 1:353-402. doi:10.1146/annurev.cb.01.110185.002033

27. Edwards M, Zwolak A, Schafer DA, Sept D, Dominguez R, Cooper JA (2014) Capping protein regulators fine-tune actin assembly dynamics. Nat Rev Mol Cell Biol 15(10):677-689. doi:10.1038/nrm3869

28. Disanza A, Carlier MF, Stradal TE, Didry D, Frittoli E, Confalonieri S, Croce A, Wehland J, Di Fiore PP, Scita G (2004) Eps8 controls actin-based motility by capping the barbed ends of actin filaments. Nat Cell Biol 6(12):1180-1188. doi:10.1038/ ncb1199

29. Helfer E, Nevalainen EM, Naumanen P, Romero S, Didry D, Pantaloni D, Lappalainen P, Carlier MF (2006) Mammalian twinfilin sequesters ADP-G-actin and caps filament barbed ends: implications in motility. EMBO J 25(6):1184-1195. doi:10. 1038/sj.emboj.7601019

30. Pelikan-Conchaudron A, Le Clainche C, Didry D, Carlier MF (2011) The IQGAP1 protein is a calmodulin-regulated barbed end capper of actin filaments: possible implications in its function in cell migration. J Biol Chem 286(40):35119-35128. doi:10.1074/jbc.M111.258772

31. Yu FX, Johnston PA, Sudhof TC, Yin HL (1990) gCap39, a calcium ion- and polyphosphoinositide-regulated actin capping protein. Science 250(4986):1413-1415

32. Sinnar SA, Antoku S, Saffin JM, Cooper JA, Halpain S (2014) Capping protein is essential for cell migration in vivo and for filopodial morphology and dynamics. Mol Biol Cell 25(14):2152-2160. doi:10.1091/mbc.E13-12-0749

33. Carlier MF, Pantaloni D (1997) Control of actin dynamics in cell motility. J Mol Biol 269(4):459-467. doi:10.1006/jmbi.1997. 1062

34. Hug C, Jay PY, Reddy I, McNally JG, Bridgman PC, Elson EL, Cooper JA (1995) Capping protein levels influence actin assembly and cell motility in dictyostelium. Cell 81(4):591-600 (pii: 0092-8674(95)900802)

35. Wiesner S, Helfer E, Didry D, Ducouret G, Lafuma F, Carlier MF, Pantaloni D (2003) A biomimetic motility assay provides insight into the mechanism of actin-based motility. J Cell Biol 160(3):387-398. doi:10.1083/jcb.200207148 
36. Hu L, Papoian GA (2010) Mechano-chemical feedbacks regulate actin mesh growth in lamellipodial protrusions. Biophys $\mathbf{J}$ 98(8):1375-1384. doi:10.1016/j.bpj.2009.11.054

37. Hu L, Papoian GA (2011) How does the antagonism between capping and anti-capping proteins affect actin network dynamics? J Phys: Condens Matter 23(37):374101. doi:10.1088/09538984/23/37/374101

38. Walsh TP, Weber A, Higgins J, Bonder EM, Mooseker MS (1984) Effect of villin on the kinetics of actin polymerization. Biochemistry 23(12):2613-2621

39. Carlier MF, Pantaloni D (1994) Actin assembly in response to extracellular signals: role of capping proteins, thymosin beta 4 and profilin. Semin Cell Biol 5(3):183-191

40. Wear MA, Yamashita A, Kim K, Maeda Y, Cooper JA (2003) How capping protein binds the barbed end of the actin filament. Curr Biol 13(17):1531-1537 (pii: S0960982203005591)

41. Takeda S, Minakata S, Koike R, Kawahata I, Narita A, Kitazawa M, Ota M, Yamakuni T, Maeda Y, Nitanai Y (2010) Two distinct mechanisms for actin capping protein regulation-steric and allosteric inhibition. PLoS Biol 8(7):e1000416. doi:10.1371/ journal.pbio. 1000416

42. Kim T, Cooper JA, Sept D (2010) The interaction of capping protein with the barbed end of the actin filament. J Mol Biol 404(5):794-802. doi:10.1016/j.jmb.2010.10.017

43. Narita A, Takeda S, Yamashita A, Maeda Y (2006) Structural basis of actin filament capping at the barbed-end: a cryo-electron microscopy study. EMBO J 25(23):5626-5633. doi:10.1038/sj. emboj. 7601395

44. Hansen SD, Mullins RD (2010) VASP is a processive actin polymerase that requires monomeric actin for barbed end association. J Cell Biol 191(3):571-584. doi:10.1083/jcb.201003014

45. Dahlgaard K, Raposo AA, Niccoli T, St Johnston D (2007) Capu and Spire assemble a cytoplasmic actin mesh that maintains microtubule organization in the Drosophila oocyte. Dev Cell 13(4):539-553. doi:10.1016/j.devcel.2007.09.003

46. Manseau L, Calley J, Phan H (1996) Profilin is required for posterior patterning of the Drosophila oocyte. Development 122(7):2109-2116

47. Wellington A, Emmons S, James B, Calley J, Grover M, Tolias P, Manseau L (1999) Spire contains actin binding domains and is related to ascidian posterior end mark-5. Development 126(23):5267-5274

48. Zigmond SH, Evangelista M, Boone C, Yang C, Dar AC, Sicheri F, Forkey J, Pring M (2003) Formin leaky cap allows elongation in the presence of tight capping proteins. Curr Biol 13(20):1820-1823 (pii: S0960982203007425)

49. Kapus A, Janmey P (2013) Plasma membrane-cortical cytoskeleton interactions: a cell biology approach with biophysical considerations. Compr Physiol 3(3):1231-1281. doi:10.1002/ cphy.c120015

50. McMahon HT, Gallop JL (2005) Membrane curvature and mechanisms of dynamic cell membrane remodelling. Nature 438(7068):590-596. doi:10.1038/nature04396

51. Scita G, Confalonieri S, Lappalainen P, Suetsugu S (2008) IRSp53: crossing the road of membrane and actin dynamics in the formation of membrane protrusions. Trends Cell Biol 18(2):52-60. doi:10.1016/j.tcb.2007.12.002

52. Goode BL, Eck MJ (2007) Mechanism and function of formins in the control of actin assembly. Annu Rev Biochem 76:593-627. doi:10.1146/annurev.biochem.75.103004.142647

53. Kovar DR, Wu JQ, Pollard TD (2005) Profilin-mediated competition between capping protein and formin Cdc12p during cytokinesis in fission yeast. Mol Biol Cell 16(5):2313-2324. doi:10.1091/mbc.E04-09-0781

54. Otomo T, Tomchick DR, Otomo C, Panchal SC, Machius M, Rosen MK (2005) Structural basis of actin filament nucleation and processive capping by a formin homology 2 domain. Nature 433(7025):488-494. doi:10.1038/nature03251

55. Pring M, Evangelista M, Boone C, Yang C, Zigmond SH (2003) Mechanism of formin-induced nucleation of actin filaments. Biochemistry 42(2):486-496. doi:10.1021/bi026520j

56. Mizuno H, Higashida C, Yuan Y, Ishizaki T, Narumiya S, Watanabe N (2011) Rotational movement of the formin mDial along the double helical strand of an actin filament. Science 331(6013):80-83. doi:10.1126/science.1197692

57. Jegou A, Carlier MF, Romet-Lemonne G (2013) Formin mDia1 senses and generates mechanical forces on actin filaments. Nat Commun 4:1883. doi: $10.1038 /$ comms 2888

58. Chesarone M, Gould CJ, Moseley JB, Goode BL (2009) Displacement of formins from growing barbed ends by bud14 is critical for actin cable architecture and function. Dev Cell 16(2):292-302. doi:10.1016/j.devcel.2008.12.001

59. Gould CJ, Chesarone-Cataldo M, Alioto SL, Salin B, Sagot I, Goode BL (2014) Saccharomyces cerevisiae Kelch proteins and Bud14 protein form a stable $520-\mathrm{kDa}$ formin regulatory complex that controls actin cable assembly and cell morphogenesis. J Biol Chem 289(26):18290-18301. doi:10.1074/jbc.M114. 548719

60. Higashida C, Miyoshi T, Fujita A, Oceguera-Yanez F, Monypenny J, Andou Y, Narumiya S, Watanabe N (2004) Actin polymerization-driven molecular movement of mDia1 in living cells. Science 303(5666):2007-2010. doi:10.1126/science.1093923

61. Bovellan M, Romeo Y, Biro M, Boden A, Chugh P, Yonis A, Vaghela M, Fritzsche M, Moulding D, Thorogate R, Jegou A, Thrasher AJ, Romet-Lemonne G, Roux PP, Paluch EK, Charras G (2014) Cellular control of cortical actin nucleation. Curr Biol 24(14):1628-1635. doi:10.1016/j.cub.2014.05.069

62. Chia PH, Chen B, Li P, Rosen MK, Shen K (2014) Local F-actin network links synapse formation and axon branching. Cell 156(1-2):208-220. doi:10.1016/j.cell.2013.12.009

63. Hotulainen P, Hoogenraad CC (2010) Actin in dendritic spines: connecting dynamics to function. J Cell Biol 189(4):619-629. doi:10.1083/jcb.201003008

64. Grassart A, Cheng AT, Hong SH, Zhang F, Zenzer N, Feng Y, Briner DM, Davis GD, Malkov D, Drubin DG (2014) Actin and dynamin2 dynamics and interplay during clathrin-mediated endocytosis. J Cell Biol 205(5):721-735. doi:10.1083/jcb. 201403041

65. Roth MG (2007) Integrating actin assembly and endocytosis. Dev Cell 13(1):3-4. doi:10.1016/j.devcel.2007.06.005

66. Yu X, Zech T, McDonald L, Gonzalez EG, Li A, Macpherson I, Schwarz JP, Spence H, Futo K, Timpson P, Nixon C, Ma Y, Anton IM, Visegrady B, Insall RH, Oien K, Blyth K, Norman JC, Machesky LM (2012) N-WASP coordinates the delivery and F-actin-mediated capture of MT1-MMP at invasive pseudopods. J Cell Biol 199(3):527-544. doi:10.1083/jcb.201203025

67. Chazeau A, Mehidi A, Nair D, Gautier JJ, Leduc C, Chamma I, Kage F, Kechkar A, Thoumine O, Rottner K, Choquet D, Gautreau A, Sibarita JB, Giannone G (2014) Nanoscale segregation of actin nucleation and elongation factors determines dendritic spine protrusion. EMBO J 33(23):2745-2764. doi:10. 15252/embj.201488837

68. Wegner AM, Nebhan CA, Hu L, Majumdar D, Meier KM, Weaver AM, Webb DJ (2008) N-wasp and the arp2/3 complex are critical regulators of actin in the development of dendritic spines and synapses. J Biol Chem 283(23):15912-15920. doi:10. 1074/jbc.M801555200

69. Linder S, Higgs H, Hufner K, Schwarz K, Pannicke U, Aepfelbacher M (2000) The polarization defect of WiskottAldrich syndrome macrophages is linked to dislocalization of the Arp2/3 complex. J Immunol 165(1):221-225 (pii: ji_v165n1p221) 
70. Qualmann B, Kessels MM (2002) Endocytosis and the cytoskeleton. Int Rev Cytol 220:93-144

71. Wu SK, Gomez GA, Michael M, Verma S, Cox HL, Lefevre JG, Parton RG, Hamilton NA, Neufeld Z, Yap AS (2014) Cortical F-actin stabilization generates apical-lateral patterns of junctional contractility that integrate cells into epithelia. Nat Cell Biol 16(2):167-178. doi:10.1038/ncb2900

72. Yamaguchi H, Lorenz M, Kempiak S, Sarmiento C, Coniglio S, Symons M, Segall J, Eddy R, Miki H, Takenawa T, Condeelis J (2005) Molecular mechanisms of invadopodium formation: the role of the N-WASP-Arp2/3 complex pathway and cofilin. J Cell Biol 168(3):441-452. doi:10.1083/jcb.200407076

73. Derivery E, Sousa C, Gautier JJ, Lombard B, Loew D, Gautreau A (2009) The Arp2/3 activator WASH controls the fission of endosomes through a large multiprotein complex. Dev Cell 17(5):712-723. doi:10.1016/j.devcel.2009.09.010

74. Duleh SN, Welch MD (2010) WASH and the Arp2/3 complex regulate endosome shape and trafficking. Cytoskeleton (Hoboken) 67(3):193-206. doi:10.1002/cm.20437

75. Campellone KG, Webb NJ, Znameroski EA, Welch MD (2008) WHAMM is an Arp2/3 complex activator that binds microtubules and functions in ER to Golgi transport. Cell 134(1):148-161. doi:10.1016/j.cell.2008.05.032

76. Rottner K, Hanisch J, Campellone KG (2010) WASH, WHAMM and JMY: regulation of Arp2/3 complex and beyond. Trends Cell Biol 20(11):650-661. doi:10.1016/j.tcb.2010.08.014

77. Basu R, Chang F (2011) Characterization of dip1p reveals a switch in Arp2/3-dependent actin assembly for fission yeast endocytosis. Curr Biol 21(11):905-916. doi:10.1016/j.cub.2011. 04.047

78. Kim DJ, Kim SH, Lim CS, Choi KY, Park CS, Sung BH, Yeo MG, Chang S, Kim JK, Song WK (2006) Interaction of SPIN90 with the Arp2/3 complex mediates lamellipodia and actin comet tail formation. J Biol Chem 281(1):617-625. doi:10.1074/jbc. M504450200

79. Wagner AR, Luan Q, Liu SL, Nolen BJ (2013) Dip1 defines a class of Arp2/3 complex activators that function without preformed actin filaments. Curr Biol 23(20):1990-1998. doi:10. 1016/j.cub.2013.08.029

80. Jia D, Gomez TS, Metlagel Z, Umetani J, Otwinowski Z, Rosen MK, Billadeau DD (2010) WASH and WAVE actin regulators of the Wiskott-Aldrich syndrome protein (WASP) family are controlled by analogous structurally related complexes. Proc Natl Acad Sci USA 107(23):10442-10447. doi:10.1073/pnas. 0913293107

81. Park L, Thomason PA, Zech T, King JS, Veltman DM, Carnell M, Ura S, Machesky LM, Insall RH (2013) Cyclical action of the WASH complex: FAM21 and capping protein drive WASH recycling, not initial recruitment. Dev Cell 24(2):169-181. doi:10.1016/j.devcel.2012.12.014

82. Rotty JD, Wu C, Bear JE (2013) New insights into the regulation and cellular functions of the ARP $2 / 3$ complex. Nat Rev Mol Cell Biol 14(1):7-12. doi:10.1038/nrm3492

83. Veltman DM, Insall RH (2010) WASP family proteins: their evolution and its physiological implications. Mol Biol Cell 21(16):2880-2893. doi:10.1091/mbc.E10-04-0372

84. Boujemaa-Paterski R, Gouin E, Hansen G, Samarin S, Le Clainche C, Didry D, Dehoux P, Cossart P, Kocks C, Carlier MF, Pantaloni D (2001) Listeria protein ActA mimics WASp family proteins: it activates filament barbed end branching by Arp2/3 complex. Biochemistry 40(38):11390-11404 (pii: bi010486b)

85. Skoble J, Portnoy DA, Welch MD (2000) Three regions within ActA promote Arp2/3 complex-mediated actin nucleation and Listeria monocytogenes motility. J Cell Biol 150(3):527-538
86. Weisswange I, Newsome TP, Schleich S, Way M (2009) The rate of N-WASP exchange limits the extent of ARP2/3-complex-dependent actin-based motility. Nature 458(7234):87-91. doi: 10.1038 /nature 07773

87. Delatour V, Helfer E, Didry D, Le KH, Gaucher JF, Carlier MF, Romet-Lemonne G (2008) Arp2/3 controls the motile behavior of N-WASP-functionalized GUVs and modulates N-WASP surface distribution by mediating transient links with actin filaments. Biophys J 94(12):4890-4905. doi:10.1529/biophysj. 107.118653

88. Mogilner A, Oster G (2003) Force generation by actin polymerization II: the elastic ratchet and tethered filaments. Biophys J 84(3):1591-1605. doi:10.1016/S0006-3495(03)74969-8

89. Amann KJ, Pollard TD (2001) The Arp $2 / 3$ complex nucleates actin filament branches from the sides of pre-existing filaments. Nat Cell Biol 3(3):306-310. doi:10.1038/35060104

90. Blanchoin L, Amann KJ, Higgs HN, Marchand JB, Kaiser DA, Pollard TD (2000) Direct observation of dendritic actin filament networks nucleated by Arp $2 / 3$ complex and WASP/Scar proteins. Nature 404(6781):1007-1011. doi:10.1038/35010008

91. Amann KJ, Pollard TD (2001) Direct real-time observation of actin filament branching mediated by Arp $2 / 3$ complex using total internal reflection fluorescence microscopy. Proc Natl Acad Sci USA 98(26):15009-15013. doi:10.1073/pnas.211556398

92. Fujiwara I, Suetsugu S, Uemura S, Takenawa T, Ishiwata $S$ (2002) Visualization and force measurement of branching by Arp2/3 complex and N-WASP in actin filament. Biochem Biophys Res Commun 293(5):1550-1555. doi:10.1016/S0006291X(02)00421-7

93. Risca VI, Wang EB, Chaudhuri O, Chia JJ, Geissler PL, Fletcher DA (2012) Actin filament curvature biases branching direction. Proc Natl Acad Sci USA 109(8):2913-2918. doi:10.1073/pnas. 1114292109

94. Smith BA, Daugherty-Clarke K, Goode BL, Gelles J (2013) Pathway of actin filament branch formation by Arp2/3 complex revealed by single-molecule imaging. Proc Natl Acad Sci USA 110(4):1285-1290. doi:10.1073/pnas.1211164110

95. Smith BA, Padrick SB, Doolittle LK, Daugherty-Clarke K, Correa IR Jr, Xu MQ, Goode BL, Rosen MK, Gelles J (2013) Three-color single molecule imaging shows WASP detachment from Arp $2 / 3$ complex triggers actin filament branch formation. Elife 2:e01008. doi:10.7554/eLife.01008

96. Le Clainche C, Didry D, Carlier MF, Pantaloni D (2001) Activation of Arp $2 / 3$ complex by Wiskott-Aldrich Syndrome protein is linked to enhanced binding of ATP to Arp2. J Biol Chem 276(50):46689-46692. doi:10.1074/jbc.C100476200

97. Gournier H, Goley ED, Niederstrasser H, Trinh T, Welch MD (2001) Reconstitution of human Arp2/3 complex reveals critical roles of individual subunits in complex structure and activity. Mol Cell 8(5):1041-1052 (pii: S1097-2765(01)00393-8)

98. Nolen BJ, Pollard TD (2008) Structure and biochemical properties of fission yeast Arp2/3 complex lacking the Arp2 subunit. J Biol Chem 283(39):26490-26498. doi:10.1074/jbc.M80260 7200

99. Egile C, Loisel TP, Laurent V, Li R, Pantaloni D, Sansonetti PJ, Carlier MF (1999) Activation of the CDC42 effector N-WASP by the Shigella flexneri IcsA protein promotes actin nucleation by Arp2/3 complex and bacterial actin-based motility. J Cell Biol 146(6):1319-1332

100. Higgs HN, Blanchoin L, Pollard TD (1999) Influence of the C terminus of Wiskott-Aldrich syndrome protein (WASp) and the Arp $2 / 3$ complex on actin polymerization. Biochemistry 38(46):15212-15222 (pii: bi991843 +)

101. Co C, Wong DT, Gierke S, Chang V, Taunton J (2007) Mechanism of actin network attachment to moving membranes: 
barbed end capture by N-WASP WH2 domains. Cell 128(5):901-913. doi:10.1016/j.cell.2006.12.049

102. Khanduja N, Kuhn JR (2014) Processive acceleration of actin barbed-end assembly by N-WASP. Mol Biol Cell 25(1):55-65. doi:10.1091/mbc.E12-11-0781

103. Boczkowska M, Rebowski G, Petoukhov MV, Hayes DB, Svergun DI, Dominguez R (2008) X-ray scattering study of activated Arp $2 / 3$ complex with bound actin-WCA. Structure 16(5):695-704. doi:10.1016/j.str.2008.02.013

104. Panchal SC, Kaiser DA, Torres E, Pollard TD, Rosen MK (2003) A conserved amphipathic helix in WASP/Scar proteins is essential for activation of Arp2/3 complex. Nat Struct Biol 10(8):591-598. doi:10.1038/nsb952

105. Rouiller I, Xu XP, Amann KJ, Egile C, Nickell S, Nicastro D, Li R, Pollard TD, Volkmann N, Hanein D (2008) The structural basis of actin filament branching by the Arp $2 / 3$ complex. J Cell Biol 180(5):887-895. doi:10.1083/jcb.200709092

106. Xu XP, Rouiller I, Slaughter BD, Egile C, Kim E, Unruh JR, Fan X, Pollard TD, Li R, Hanein D, Volkmann N (2012) Threedimensional reconstructions of Arp2/3 complex with bound nucleation promoting factors. EMBO J 31(1):236-247. doi:10. 1038/emboj.2011.343

107. Mullins RD, Kelleher JF, Xu J, Pollard TD (1998) Arp $2 / 3$ complex from Acanthamoeba binds profilin and cross-links actin filaments. Mol Biol Cell 9(4):841-852

108. Gaucher JF, Mauge C, Didry D, Guichard B, Renault L, Carlier MF (2012) Interactions of isolated C-terminal fragments of neural Wiskott-Aldrich syndrome protein (N-WASP) with actin and Arp2/3 complex. J Biol Chem 287(41):34646-34659. doi:10.1074/jbc.M112.394361

109. Padrick SB, Doolittle LK, Brautigam CA, King DS, Rosen MK (2011) Arp2/3 complex is bound and activated by two WASP proteins. Proc Natl Acad Sci USA 108(33):E472-E479. doi:10. 1073/pnas. 1100236108

110. Ti SC, Jurgenson CT, Nolen BJ, Pollard TD (2011) Structural and biochemical characterization of two binding sites for nucleation-promoting factor WASp-VCA on Arp2/3 complex. Proc Natl Acad Sci USA 108(33):E463-E471. doi:10.1073/ pnas. 1100125108

111. Hetrick B, Han MS, Helgeson LA, Nolen BJ (2013) Small molecules CK-666 and CK-869 inhibit actin-related protein 2/3 complex by blocking an activating conformational change. Chem Biol 20(5):701-712. doi:10.1016/j.chembiol.2013.03.019

112. Luan Q, Nolen BJ (2013) Structural basis for regulation of Arp2/ 3 complex by GMF. Nat Struct Mol Biol 20(9):1062-1068. doi: $10.1038 / \mathrm{nsmb} .2628$

113. Jasnin M, Asano S, Gouin E, Hegerl R, Plitzko JM, Villa E, Cossart P, Baumeister W (2013) Three-dimensional architecture of actin filaments in Listeria monocytogenes comet tails. Proc Natl Acad Sci USA 110(51):20521-20526. doi:10.1073/pnas. 1320155110

114. Sechi AS, Wehland J, Small JV (1997) The isolated comet tail pseudopodium of Listeria monocytogenes: a tail of two actin filament populations, long and axial and short and random. J Cell Biol 137(1):155-167

115. Mueller J, Pfanzelter J, Winkler C, Narita A, Le Clainche C, Nemethova M, Carlier MF, Maeda Y, Welch MD, Ohkawa T, Schmeiser C, Resch GP, Small JV (2014) Electron tomography and simulation of baculovirus actin comet tails support a tethered filament model of pathogen propulsion. PLoS Biol 12(1):e1001765. doi:10.1371/journal.pbio.1001765

116. Steffen A, Faix J, Resch GP, Linkner J, Wehland J, Small JV, Rottner K, Stradal TE (2006) Filopodia formation in the absence of functional WAVE- and Arp2/3-complexes. Mol Biol Cell 17(6):2581-2591. doi:10.1091/mbc.E05-11-1088

117. Tee YH, Shemesh T, Thiagarajan V, Hariadi RF, Anderson KL, Page C, Volkmann N, Hanein D, Sivaramakrishnan S, Kozlov MM, Bershadsky AD (2015) Cellular chirality arising from the self-organization of the actin cytoskeleton. Nat Cell Biol 17(4):445-457. doi:10.1038/ncb3137

118. Haglund CM, Choe JE, Skau CT, Kovar DR, Welch MD (2010) Rickettsia Sca2 is a bacterial formin-like mediator of actinbased motility. Nat Cell Biol 12(11):1057-1063. doi:10.1038/ ncb2109

119. Nakajima O, Nakamura F, Yamashita N, Tomita Y, Suto F, Okada T, Iwamatsu A, Kondo E, Fujisawa H, Takei K, Goshima Y (2006) FKBP133: a novel mouse FK506-binding protein homolog alters growth cone morphology. Biochem Biophys Res Commun 346(1):140-149. doi:10.1016/j.bbrc.2006.05.113

120. Reed SC, Lamason RL, Risca VI, Abernathy E, Welch MD (2014) Rickettsia actin-based motility occurs in distinct phases mediated by different actin nucleators. Curr Biol 24(1):98-103. doi:10.1016/j.cub.2013.11.025

121. Viklund IM, Aspenstrom P, Meas-Yedid V, Zhang B, Kopec J, Agren D, Schneider G, D'Amato M, Olivo-Marin JC, Sansonetti P, Van Nhieu GT, Pettersson S (2009) WAFL, a new protein involved in regulation of early endocytic transport at the intersection of actin and microtubule dynamics. Exp Cell Res 315(6):1040-1052. doi:10.1016/j.yexcr.2008.12.004

122. Kabsch W, Mannherz HG, Suck D, Pai EF, Holmes KC (1990) Atomic structure of the actin:DNase I complex. Nature 347(6288):37-44. doi:10.1038/347037a0

123. Oda T, Iwasa M, Aihara T, Maeda Y, Narita A (2009) The nature of the globular- to fibrous-actin transition. Nature 457(7228):441-445. doi:10.1038/nature07685

124. Behrmann E, Muller M, Penczek PA, Mannherz HG, Manstein DJ, Raunser S (2012) Structure of the rigor actin-tropomyosinmyosin complex. Cell 150(2):327-338. doi:10.1016/j.cell.2012. 05.037

125. Rebowski G, Namgoong S, Boczkowska M, Leavis PC, Navaza J, Dominguez R (2010) Structure of a longitudinal actin dimer assembled by tandem w domains: implications for actin filament nucleation. J Mol Biol 403(1):11-23. doi:10.1016/j.jmb.2010. 08.04 